\title{
Proposição do índice "fração vegetada" e sua relação com alterações na temperatura do ar e no conforto térmico no período diurno e em situação de verão para Curitiba
}

\author{
Proposition of a "vegetation fraction" index and its \\ relationship with air temperature and thermal comfort \\ changes during daytime in summer in Curitiba
}

\section{Flavia Cristina Osaku Minella Eduardo Leite Krüger}

\section{Resumo}

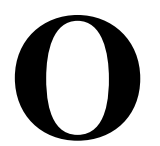

artigo avalia o impacto da inserção de áreas verdes na diminuição do estresse térmico do pedestre em dias com desconforto por calor. Está focado em duas importantes ações voltadas à mobilidade urbana que consideraram a inserção de vegetação como estratégia de requalificação da paisagem urbana, em Curitiba: (1) o projeto para a implantação do primeiro metrô do Estado do Paraná e (2) a transformação da antiga Rodovia Federal BR-116 em via urbana. Considerando recortes urbanos relacionados a tais projetos como áreas de estudo (Sete de Setembro e Linha Verde), o objetivo da pesquisa é propor um índice que indique a cobertura vegetal necessária para haver reduções na temperatura do ar na escala do pedestre, considerando o período diurno em situação de verão. Adicionalmente, analisa-se o impacto no conforto térmico, por meio do universal thermal climate index (UTCI). Para isso, foram utilizadas medições em campo para a coleta de dados microclimáticos, bem como simulações computacionais com a ferramenta ENVI-met. Os resultados apontam que seria necessário um aumento de cerca de $70 \%$ de cobertura vegetal para uma redução de $1^{\circ} \mathrm{C}$ na temperatura ambiente média da área estudada, o que indica o potencial de resfriamento de áreas vegetadas em situações urbanas.

Palavras-chaves: Áreas verdes. Conforto térmico. Simulação computacional. Índice "fração vegetada".

Flavia Cristina Osaku Minella Universidade Tecnológica Federal do Curitiba PR - Brasil

Eduardo Leite Krüger Universidade Tecnológica Federal do

Paraná

Curitiba - PR - Brasil

Recebido em 26/03/16 Aceito em 12/08/16

\begin{abstract}
This paper analyses the impact of the introduction of green areas on the reduction of pedestrian heat stress in days with heat discomfort. The paper focuses on two relevant urban mobility initiatives that use greenery enhancement as a strategy for the requalification of urban environments in Curitiba: (1) the proposal of the first underground railway system in the state and (2) the transformation of an interstate highway into an urban avenue. Segments of such projects are evaluated as study areas (Sete de Setembro and Linha Verde) with the aim of proposing an index that estimates the vegetation cover needed to promote air temperature drops at the pedestrian scale during daytime in summer. Additionally, the study analyses the impact on thermal comfort through the universal thermal climate index (UTCI). For that purpose, we carried out a field study where we monitored relevant meteorological data, as well as computer simulations using the ENVI-met model. Results suggest that an increase of $70 \%$ in vegetated fraction would be needed to offset $1^{\circ} \mathrm{C}$ in mean ambient temperature in the area analysed, which represents the cooling potential of vegetation fractions in urban conditions.
\end{abstract}

Keywords: Green areas. Thermal comfort. Computer simulation. "Vegetated fraction" index. 


\section{Introdução}

A presença de árvores no ambiente urbano pode afetar o campo térmico individual de ruas e até mesmo produzir modificações na escala da cidade. Sob agrupamentos de árvores de copa densa, a redução na temperatura do ar (Ta) chega a ser até $4^{\circ} \mathrm{C}$, comparativamente a áreas com exposição direta à radiação solar (COHEN; POTCHTER; MATZARAKIS, 2012; MASCARÓ, 1996). Segundo Bowler et al. (2010), com base na revisão de 24 estudos que consideraram a observação de 125 parques urbanos, foi possível constatar que áreas vegetadas podem apresentar, em relação ao entorno imediato, uma redução média de $0,94^{\circ} \mathrm{C}$ na temperatura ambiente durante o dia. A extensão das áreas vegetadas bem como os arranjos e as disposições das árvores estão relacionados à magnitude de tal efeito. Labaki et al. (2011) destacam o papel termorregulador dos componentes morfoanatômicos das árvores e Martini (2011) considera que o estudo fenológico das espécies arbóreas contribui para a eficiência e o desempenho delas no ambiente urbano.

Ao impactar na qualidade do ar e no clima, e, portanto, na qualidade de vida (LOIS; LABAKI, 2001), as áreas verdes podem auxiliar no incremento do conforto térmico externo e na obtenção de níveis mais baixos de estresse térmico em dias com desconforto por calor. Conforme Erell, Pearlmutter e Williamson (2011), para essa situação ser factível duas condições são necessárias: (1) o ar não pode estar extremamente quente (superior a $35^{\circ} \mathrm{C}$ ) nem muito úmido e (2) o fluxo de ar deve ser mantido a uma determinada taxa. Essa constatação é determinante para a dissipação de calor pelo corpo humano por convecção e evaporação, influenciando diretamente no balanço de energia ao nível do pedestre.

Como estratégia para adaptação das cidades adensadas ao fenômeno de aquecimento (incluindo ondas de calor), Duarte (2015) sugere que a vegetação deve ser distribuída no espaço urbano em praças, parques, ruas e demais espaços públicos, em uma sucessão de áreas abertas ou semiconfinadas, formando uma infraestrutura verde, a qual poderia apoiar estrátegias de mobilidade e proporcionar espaços de amenidade climática.

Especialmente em Curitiba, a criação de uma infraestrutura verde ganha importância, resolvendo problemas de concentração e má distribuição das áreas vegetadas (MENDONÇA, 2002), mesmo que o índice oficial de área verde por habitante de $64,5 \mathrm{~m} 2$ seja um dos mais elevados do país (CURITIBA, 2012). Leal, Biondi e Batista (2014) constataram uma diferença de até $3,3^{\circ} \mathrm{C}$ na Ta durante medições de 44 pontos estabelecidos em quatro transectos na cidade de Curitiba, sendo os valores mais baixos de Ta associados à presença das florestas urbanas e à baixa densidade de construção.

Os métodos de avaliação dos efeitos da vegetação no clima podem envolver, além das medições da temperatura do ar e/ou da temperatura de superfície, análises de imagens aéreas infravermelhas, de modelos físicos e, ainda, de simulação computacional. Algumas pesquisas utilizaram a ferramenta computacional ENVI-met para analisar a influência de variáveis de desenho urbano e/ou vegetação no ambiente urbano, como: Ali-Toudert (2005) para a região do Mzab/Algeria, Chen e Wong (2006) para Singapura, Spangenberg et al. (2008) e Minella, Honjo e Krüger (2012) para São Paulo, Fahmy e Sharples (2009) para a cidade de Cairo/Egito e Ng et al. (2012) para Hong Kong/China.

O reconhecimento da importância da vegetação por parte dos gestores urbanos reflete nas políticas públicas que visam incorporar as áreas verdes dos lotes à infraestrutura verde citadina. Ong (2003) propôs o indicador denominado green plot ratio (GnPR) adotado pela legislação de Singapura. GnPR está baseado no conceito de índice de área foliar (IAF), parâmetro adimensional definido por Watson (1947) como a relação entre a área foliar da copa pela unidade de superfície projetada no solo em $\left(\mathrm{em} \mathrm{m}^{2} / \mathrm{m}^{2}\right)$, sendo o IAF médio para um determinado lote.

Em Berlim, desde 1997 o planejamento urbano estabeleceu a metodologia intitulada biotope area factor (BAF), expresso pela relação entre a área das superfícies ecologicamente eficientes e a área total do lote. São ponderadas as diversas parcelas de área do lote, proporcionando a avaliação da estabilidade ecológica (BETTINE et al., 2012). Assim, novos espaços urbanos são integrados à infraestrutura verde existente na cidade. A partir do BAF, surgiram outras variações, como o Green Space Factor em Malmö (Suécia) e em Southampton (Reino Unido), o Seattle Green Factor em Seattle (Estados Unidos) e o Green Infrastructure Score no noroeste da Inglaterra (VARTHOLOMAIOS et al., 2013).

$\mathrm{Na}$ presente pesquisa, tem-se como objetivo propor um índice que indique a cobertura vegetal necessária para haver reduções na temperatura do ar na escala do pedestre, considerando o período diurno e a situação de verão. Por meio de simulação computacional, também é analisado o 
impacto no conforto térmico humano decorrente da inserção de áreas verdes no setor estrutural da avenida Sete de Setembro e na avenida Linha Verde, ambos em Curitiba.

\section{Método}

Curitiba $\left(25^{\circ} 31^{\prime} \mathrm{S}, 49^{\circ} 11^{\prime} \mathrm{W}, 917 \mathrm{~m}\right.$ acima do nível do mar), capital do Estado do Paraná, abrange uma área de $435,036 \mathrm{~km}^{2}$, possui uma população de mais de 1.800 .000 habitantes, sendo a cidade mais populosa do sul do Brasil e a oitava em nível nacional (IBGE, 2014). De acordo com a classificação de Köppen-Geiger, o clima da cidade é predominantemente mesotérmico com verões frescos $(\mathrm{Cfb})$. Entre as médias mensais, a temperatura máxima é de $26^{\circ} \mathrm{C}$ e a mínima é de $7,4^{\circ} \mathrm{C}$, e os ventos advindos do leste são comuns durante o ano todo (GOULART; LAMBERTS; FIRMINO, 1998).

A pesquisa está apoiada em coleta de dados de campo e simulação computacional com a ferramenta ENVI-met, a qual viabilizou a comparação entre cenários atuais e cenários alternativos.

Esta seção está dividida em oito partes, a saber:

(a) apresentação das áreas de estudo;

(b) método de coleta de dados microclimáticos em campo;

(c) descrição do índice de conforto térmico utilizado;

(d) modelagem das áreas de estudo;

(e) ajustes nas configurações dos modelos;

(f) validação dos resultados e testes estatísticos aplicados;

(g) simulação de um dia típico de projeto; e

(h) cenários testados.

\section{Apresentação das áreas de estudo}

Em Curitiba, o plano do metrô prevê aumentar a capacidade de transporte público dos eixos norte/sul (Santa Cândida/CIC Sul), os quais possuem maior carregamento diário. A extensão do metrô será de 22 km (CURITIBA, 2014). O diferencial projetual em relação aos comumente concebidos é o menor impacto ambiental durante a fase de construção devido ao aproveitamento do corredor central exclusivo ao transporte coletivo dos setores estruturais, parte do sistema trinário de vias. Nesses setores, o potencial construtivo (área do lote multiplicada pelo coeficiente de aproveitamento) é de 4, e não há limite de altura para as edificações, o que pode acarretar a formação de cânions urbanos. Com a liberação das canaletas exclusivas ao tráfego dos ônibus nas estruturais, prevê-se a requalificação urbana destas para uma via pedonal arborizada. O trecho do metrô abarcado nesta pesquisa está localizado no setor estrutural da avenida Sete de Setembro.

Importante projeto para a mobilidade da cidade, com a transformação de um trecho da antiga Rodovia Federal BR-116 em via urbana, a avenida Linha Verde (inaugurada em 2009) atravessa o município de norte a sul em $22 \mathrm{~km}$ (INSTITUTO...; FUNDAÇÃO..., 2012). Foram realizadas intervenções físicas voltadas ao sistema viário, ao transporte, ao uso do solo e ao meio ambiente. No escopo do projeto para meio ambiente, ressalta-se a criação de um parque linear e tratamento paisagístico, com plantio de 5.200 árvores (22 tipos de espécies nativas) (INSTITUTO...; FUNDAÇÃO..., 2012).

Em ambos os locais, a adição de área verde pode trazer alterações no microclima, sendo consideradas nesta pesquisa duas áreas de estudo, denominadas: (1) Sete de Setembro e (2) Linha Verde.

O trecho que engloba a área estudada na Sete de Setembro (Figura 1) apresenta edificações construídas conforme tipologia do Plano Massa, sem afastamento ou com afastamento lateral mínimo. Possui azimute de $67^{\circ}$ e deflexão de $23^{\circ}$ em relação ao eixo leste-oeste. A área de estudo engloba 26 quadras, limitadas no sentido transversal por duas importantes avenidas (Batel e Iguaçu).

Na Linha Verde (Figura 2), os locais sujeitos à mudança da paisagem mais significativa a partir dos parâmetros propostos de uso do solo são aqueles próximos aos pontos de parada de ônibus biarticulados (estações-tubo). Foi escolhido para a locação da estação meteorológica um ponto próximo à estação Vila Fanny (distante cerca de 7 $\mathrm{km}$ do centro da cidade). No recorte englobado nas simulações, mais precisamente na borda da avenida, predominam edifícios de dois pavimentos de uso comercial. A Linha Verde possui azimute de $37^{\circ}$ e deflexão de $53^{\circ} \mathrm{em}$ relação ao eixo leste-oeste.

\section{Método de coleta de dados microclimáticos em campo}

De modo a permitir uma comparação com os dados simulados, foram realizadas medições das variáveis microclimáticas em dois dias em cada ponto (SS1, LV1) em situação de verão, das 9 h00 às 15 h00, abrangendo parte do horário comercial quando há fluxo de pedestres nas vias. 
Figura 1 - Local de medição no setor estrutural Sete de Setembro (ponto SS1)
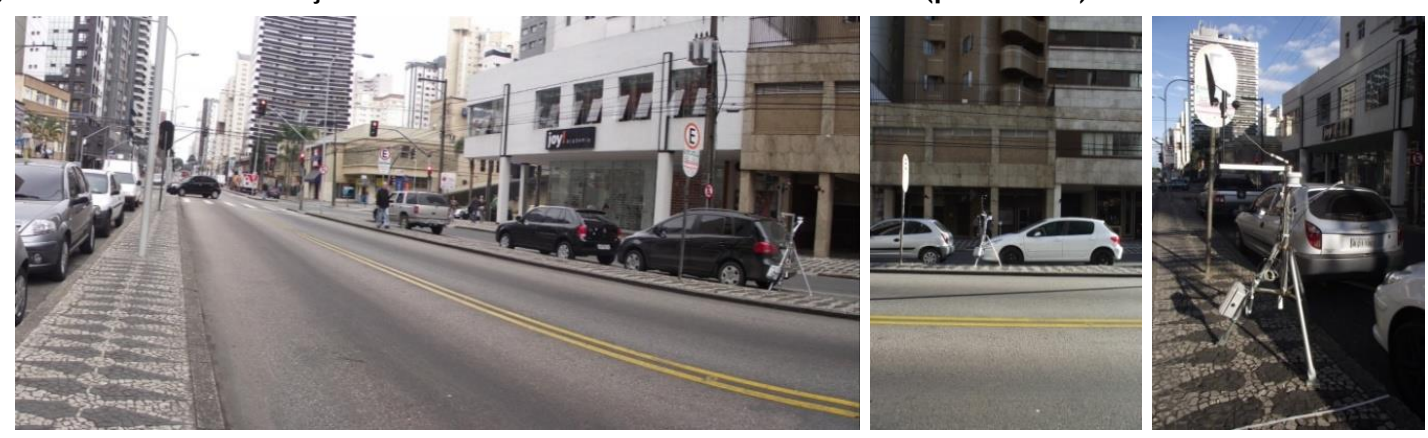

Figura 2 - Local de medição na avenida Linha Verde (ponto LV1)
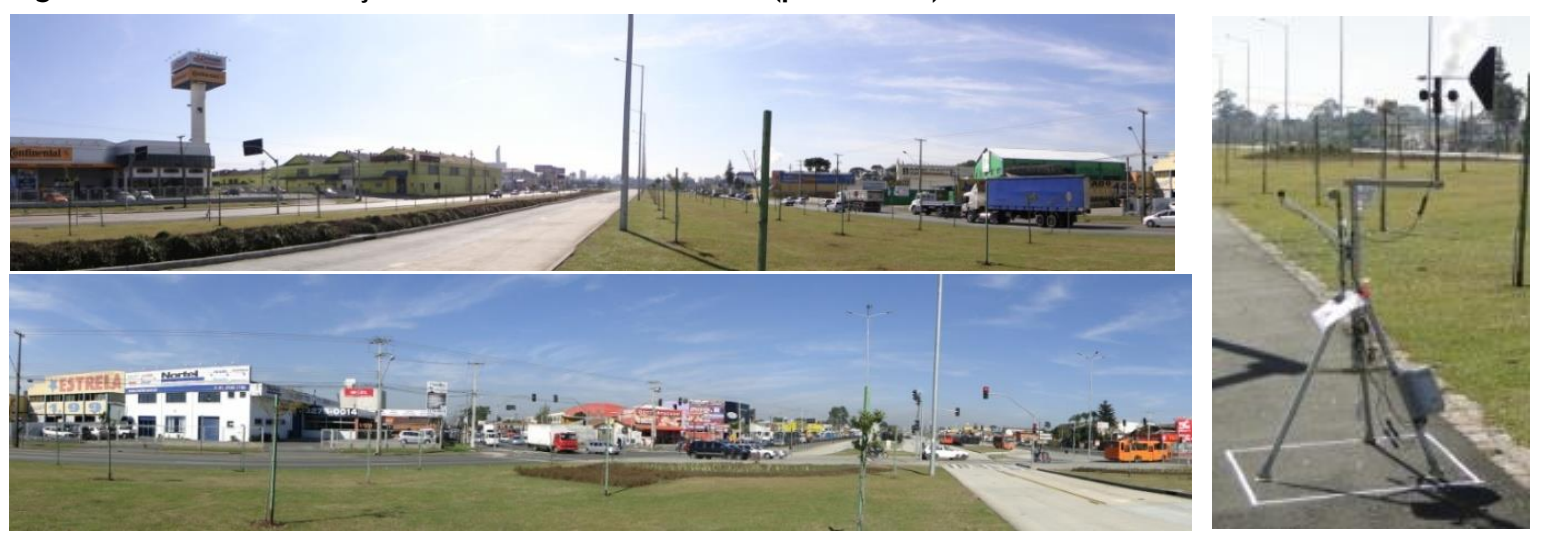

Foram utilizadas micro estações meteorológicas HOBO (H21-001) da Onset. Cada estação estava equipada com os seguintes instrumentos: sensor de temperatura e umidade (S-THB-M002) a 1,30 m do solo; piranômetro de silício (S-LIB-M003) a $1,30 \mathrm{~m}$ do solo e sensor de direção e velocidade do vento (S-WCA-M003) a $1,90 \mathrm{~m}$ do solo. Nos conjuntos de estações meteorológicas utilizaramse, também, termômetros de globo (a temperatura de globo é necessária para o cálculo da temperatura radiante média (Trm), importante variável no cálculo de índices de conforto térmico) a 1,30 m do solo, com diâmetro de duas polegadas, pintados na cor RAL-7001/cinza médio (THORSSON et al., 2007). As alturas dos instrumentos de medição seguem as recomendações da WMO (WORLD..., 2008) e da Campbell Scientific (1997).

Para todos os casos, a Trm $\left(\mathrm{em}^{\circ} \mathrm{C}\right)$ foi calculada pela fórmula para convecção forçada, definida pela norma ISO 7726 (INTERNATIONAL..., 1998) (Equação 1).

$\operatorname{Trm}=[(\mathrm{Tg}+273) 4+2,5.108$. v 0,6 (Tg-Ta) $] 1 / 4-27$ Eq. 1

Onde:

$\mathrm{v}$ é a velocidade do ar, em $\mathrm{m} / \mathrm{s}$;

Ta é a temperatura do ar, em ${ }^{\circ} \mathrm{C}$; e
Tg é a temperatura de globo, em ${ }^{\circ} \mathrm{C}$.

As faixas de precisão dos instrumentos satisfazem às recomendações da norma ISO 7726 (INTERNATIONAL..., 1998), que dispõe sobre os instrumentos para a medição de variáveis físicas. Os dados microclimáticos foram coletados a cada 10 segundos e depois compostos os minutos.

Para a seleção de um dia específico em cada ponto para posterior ajuste de dados de simulação, foi utilizada como critério a condição do céu claro em situação de verão, sendo selecionado o dia 10/3/2012 na Sete de Setembro e o dia 7/3/2012 na Linha Verde. O ponto na Sete de Setembro fica exposto à radiação solar direta até às $11 \mathrm{~h} 00$, momento a partir do qual está sujeito ao sombreamento provocado pelo entorno. Em contrapartida, o ponto de medição na Linha Verde fica exposto à radiação solar direta durante todo $o$ período de medição.

As fotos olho de peixe para obtenção do fator de visão do céu (FVC) (porção visível do céu a partir de determinado ponto, parâmetro relacionado à morfologia urbana) foram obtidas com lente Sigma Fisheye $8 \mathrm{~mm}$ F-35 acoplada à câmera Nikon D80. O conjunto foi posicionado de forma a corresponder à altura do sensor de temperatura $\mathrm{e}$ umidade do ar (1,30 m em relação ao nível do

356 Minella, F. C. O.; Krüger, E. L. 
solo). O cálculo estimado do FVC foi realizado no modelo Rayman (MATZARAKIS; RUTZ; MAYER, 2007). Esse mesmo modelo serviu para traçar a carta solar, que, sobreposta à foto olho de peixe, indica o período de incidência solar no ponto durante um ciclo diário na data desejada.

\section{Descrição do índice de conforto térmico utilizado}

$\mathrm{Na}$ análise do nível de estresse térmico é utilizado o índice de conforto térmico UTCI (JENDRITZKY et al., 2009), o qual permite a avaliação das condições de conforto térmico em espaços abertos com base na resposta fisiológica do corpo humano, obtida por meio de um modelo de conforto termo-fisiológico denominado "UTCI-Fiala".

O UTCI segue o conceito da temperatura equivalente e apresenta para o ambiente de referência as seguintes definições:

(a) $50 \%$ de umidade relativa (com pressão de vapor não excedendo $20 \mathrm{hPa}$ );

(b) temperatura do ar (Ta) igual à temperatura radiante média (Trm); e

(c) velocidade do vento de $0,5 \mathrm{~m} / \mathrm{s}$ a $10 \mathrm{~m}$ de altura.

As variáveis de entrada para o cálculo do UTCI, são: v a $10 \mathrm{~m}$ de altura $(\mathrm{m} / \mathrm{s})$, Ta $\left({ }^{\circ} \mathrm{C}\right)$, UR $(\%)$ e a diferença entre $\operatorname{Trm}$ e Ta (dada em $\left.{ }^{\circ} \mathrm{C}\right)$. A taxa metabólica é assumida como constante e igual a $150 \mathrm{~W} / \mathrm{m}^{2}$ ou 2,6 met (pessoa caminhando a 4 $\mathrm{km} / \mathrm{h}$ em terreno plano), e o grau de isolamento térmico da vestimenta é calculado a partir da Ta no UTCI (INTERNATIONAL..., 2001).

O cálculo do UTCI foi realizado on-line (http://www.utci.org/utcineu/utcineu.php). Para a conversão da velocidade do vento de $1,90 \mathrm{~m}$ para $10 \mathrm{~m}$ de altura do solo, utilizou-se a Equação 2 (OKE, 2006):

$\mathrm{v} 1 / \mathrm{vref}=\ln (\mathrm{z} 1 / \mathrm{z} 0) / \ln (\mathrm{zref} / \mathrm{z} 0)$

Eq. 2
Onde v1 é a velocidade do vento à altura desejada, vref é a velocidade do vento medido, z1 é a altura desejada, zref é a altura dos instrumentos de medição e z0 é o coeficiente de rugosidade, tendo sido adotado para z0 o valor de 0,1, típico para áreas abertas com obstáculos ocasionais (WIERINGA et al., 2001).

Para a classificação e análise das categorias de estresse térmico foram utilizadas as faixas de conforto/desconforto (Tabela 1), sugeridas por Rossi, Krüger e Bröde (2012), com base nos votos de sensação térmica coletados em campo, para Curitiba.

\section{Modelagem das áreas de estudo}

O modelo computacional utilizado para simular estratégias de melhoria do ambiente térmico urbano é o ENVI-met ${ }^{1}$, desenvolvido por Bruse e Fleer (1998), com base nas leis fundamentais da dinâmica dos fluidos e da termodinâmica, de modo a simular as interações microclimáticas no ambiente urbano com resolução padrão de $0,5 \mathrm{~m}$ até $10 \mathrm{~m}$ no espaço e de $10 \mathrm{~s}$ no tempo (BRUSE, 2012). Na pesquisa é utilizada a versão ENVI-met 3.1 Beta 5 e extensão Leonardo 3.

\section{Ajustes nas configurações dos modelos}

Os dados climáticos das estações de referência (velocidade e direção do vento a $10 \mathrm{~m}$, temperatura potencial do ar e umidade relativa do ar a 2) servem como variáveis de entrada no modelo ENVI-met. Para os estudos em Curitiba, utilizaram-se dados do Instituto Nacional de Meteorologia (INMET, disponível em: http://www.inmet.gov.br/sonabra/maps/automatica s.php). O dado de umidade específica do ar a 2.500 $\mathrm{m}$ (em $\mathrm{g} / \mathrm{kg}$ ) permanece constante durante a simulação e pode ser obtido no site da Universidade de Wyoming².

Tabela 1 - Categoria de estresse térmico para o UTCI ajustado para Curitiba

\begin{tabular}{cc}
\hline UTCI & Categorias de estresse térmico ao calor \\
\hline$>9-15^{\circ} \mathrm{C}$ & Sem estresse térmico \\
$>15-27^{\circ} \mathrm{C}$ & Conforto térmico \\
$>27-32^{\circ} \mathrm{C}$ & Moderado estresse térmico \\
$>32-38^{\circ} \mathrm{C}$ & Forte estresse térmico \\
$>38-46^{\circ} \mathrm{C}$ & Muito forte estresse térmico \\
$>46^{\circ} \mathrm{C}$ & Extremo estresse térmico \\
\hline
\end{tabular}

\footnotetext{
$1<$ http://www.envi-met.com/>.

${ }^{2}<$ http://weather.uwyo.edu/upperair/sounding.html>.
} 


\section{Validação dos resultados e testes estatísticos aplicados}

A temperatura do ar foi escolhida como variável climática de referência para a comparação entre dados medidos e simulados. Para as outras variáveis climáticas, procurou-se semelhança na obtenção de valores médios. Nesse sentido, as medições microclimáticas in loco servem de referência para os testes de convergência.

Testes estatísticos apontaram a curva com Ta fidedigna à obtida nos monitoramentos, sendo aplicados os seguintes testes: o erro médio quadrático (root mean squared error (RMSE)), o índice de concordância de Willmott (Willmott index of agreement) e o teste t-Student.

O RMSE (Equação 3) e o índice de concordância de Willmott (d) (Equação 4) indicam a exatidão do método, isto é, o afastamento entre os valores preditos e os medidos. No RSME o valor ideal é o mais próximo de zero. $O$ índice de concordância de Willmott varia de zero a 1 , sendo esta última a concordância ideal.

$$
\begin{aligned}
& \text { RSME }=\sqrt{\frac{\sum_{\mathrm{i}=1}^{\mathrm{n}}\left(\mathrm{y}_{\mathrm{i}}-\mathrm{x}_{\mathrm{i}}\right)^{2}}{\mathrm{n}}} \\
& \mathrm{d}=1-\frac{\sum_{\mathrm{i}=1}^{\mathrm{n}}\left(\mathrm{y}_{\mathrm{i}}-\mathrm{x}_{\mathrm{i}}\right)^{2}}{\sum_{\mathrm{i}=1}^{\mathrm{n}\left(\left[\mathrm{y}_{\mathrm{i}}-\mathrm{x}|+| \mathrm{x}_{\mathrm{i}}-\mathrm{x} \mid\right)^{2}\right.}}
\end{aligned}
$$

Onde:

yi é o valor estimado (temperatura predita);

xi é o valor observado (temperatura medida);

$\mathrm{x}$ é o valor médio dos valores observados; e n é o número de observações.

$\mathrm{O}$ teste t-Student é utilizado quando se pretende comparar duas médias, sendo adotado um nível de significância de 0,05 (5\%).

\section{Simulação de um dia típico de projeto}

As características de um dia típico de projeto servem como referência para o desenvolvimento de projetos que respondam as exigências termohigrométricas, proporcionando uma melhor resposta quanto ao conforto térmico. $\mathrm{O}$ dia típico lida com um dia teórico e foi desenvolvido por Goulart, Lamberts e Firmino (1998) com base na metodologia desenvolvida por Sattler (1989). Segundo os autores, a declinação solar é o parâmetro para estabelecer a data de referência. Para a pesquisa foi selecionado o dia 28/01 como data de referência, dia típico de verão nível $1 \%$.

\section{Cenários propostos}

A Figura 3 corresponde à modelagem dos cenários propostos. Em tais cenários, foi considerada a possibilidade máxima da utilização de cobertura arbórea. As áreas construídas estão representadas pela cor cinza, as superfícies gramadas pela cor verde-clara e as árvores pela cor verde-escura. Na Linha Verde os pontos LV1 e LV3 estão situados sob a copa das árvores, enquanto o ponto LV2 está situado no entorno das árvores inseridas no modelo.

Figura 3 - Cenários propostos

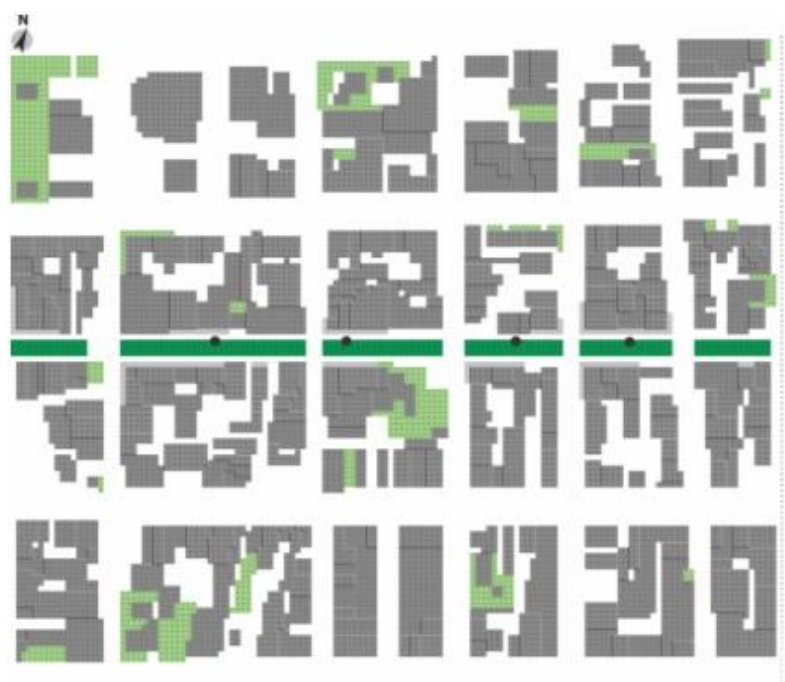

(a) Sete de Setembro

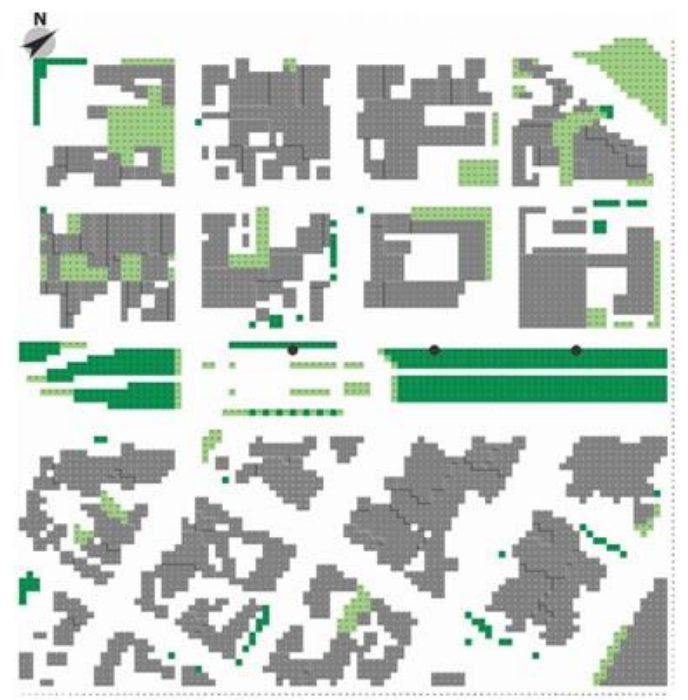

(b) Linha Verde

358 Minella, F. C. O.; Krüger, E. L. 


\section{Resultados}

Esta seção está dividido em duas etapas: avaliações dos cenários propostos e apresentação do índice proposto. Devido à complexidade inerente à simulação do microclima urbano, uma vez que diversas variáveis compreendem a sua formação, a capacidade de reprodução da situação real no ambiente de simulação será sempre limitada em algum aspecto. Nesse sentido, os resultados aqui auferidos devem ser entendidos como indicadores de tendências.

\section{Características gerais das medições e simulações realizadas}

A Tabela 2 apresenta o conjunto de variáveis climáticas monitoradas nas duas vias.

O modelo partiu de um tamanho de célula de $6 \mathrm{~m}$ x 6 m x 3 m (eixos x, y e z). No ENVI-met, para a configuração das grades verticais, são oferecidas as opções equidistantes ou telescópicas. A última opção é recomendada no caso de ser necessário incluir edificações de grande altura, sendo este o método selecionado para a geração das grades verticais nos dois casos, com fator de expansão de $20 \%$ a partir de $57 \mathrm{~m}$ de altura do solo.

$\mathrm{Na}$ direção horizontal, na área que circunda o limite da área principal, pode ser acrescentado um campo de transição bidimensional para os fluxos de vento e radiação solar, evitando, assim, instabilidades na borda da área principal. Cinco grades de célula se mostraram suficientes para ambos os locais. Para simplificação do modelo, o tipo de solo escolhido foi asfalto, tanto para a área do modelo como para as bordas do modelo. O modelo do cenário atual utilizado na Sete de
Setembro foi confeccionado por Rasia (2011). No entanto, algumas modificações se fizeram necessárias, como o tamanho da grade no eixo z e a geração do método vertical aplicado. Para as galerias advindas do Plano Massa foram consideradas grades com $3 \mathrm{~m}$ de altura e sobrelojas com $6 \mathrm{~m}$ de altura. O perímetro modelado corresponde a um domínio de $840 \mathrm{~m} \mathrm{x}$ $720 \mathrm{~m}$, totalizando uma área de $604.800 \mathrm{~m}^{2}$. Para a modelagem do cenário atual da Linha Verde foi utilizada planta cadastral cedida pela prefeitura projetada sobre imagem de satélite (GOOGLE, 2012). A altura das edificações foi realizada de maneira visual durante levantamento in loco, assumindo-se uma altura de $3 \mathrm{~m}$ por pavimento e contando-se o número de pavimentos. O recorte selecionado para o estudo compreende um perímetro de $576 \mathrm{~m}$, tanto no eixo x como no eixo $\mathrm{y}$, perfazendo $331.776,0 \mathrm{~m}^{2}$.

No modelo ENVI-met, a vegetação é representada esquematicamente por um bloco, e o corpo da planta, tanto para cima da superfície como para baixo, é dividido em 10 partes equidistantes. A divisão do corpo da planta, acima da superfície, é constituída pela densidade de área foliar (leaf area density (LAD)) (BRUSE, 2012). Para a vegetação arbórea, foi selecionada, a partir do banco de dados existente, árvores de $15 \mathrm{~m}$ de altura, copa densa e sem folhas na base (sigla T2, LAD para cada segmento: $0,000 \quad 0,000 \quad 2,180 \quad 2,180 \quad 2,180 \quad 2,180$ $2,1802,180 \quad 1,720 \quad 0,000)$. Para a superfície gramada, foi alterada a altura da grama existente no banco de dados do programa de $50 \mathrm{~cm}$ para 20 cm (sigla xx, LAD para cada segmento: 0,300 $\begin{array}{lllllllll}0,300 & 0,300 & 0,300 & 0,300 & 0,300 & 0,300 & 0,300 & 0,300\end{array}$ 0,300).

Tabela 2 - Variáveis climáticas monitoradas na Sete de Setembro e na Linha Verde

\begin{tabular}{c|c|c|c|c|c|c|c|c|c|c}
\hline \multirow{2}{*}{ Hora } & \multicolumn{9}{|c|}{ Sete de Setembro } & \multicolumn{5}{c}{ Linha Verde } \\
\cline { 2 - 11 } & $\mathbf{T a}\left({ }^{\circ} \mathbf{C}\right)$ & $\mathbf{U R}(\boldsymbol{\%})$ & $\mathbf{v}(\mathbf{m} / \mathbf{s})$ & $\mathbf{I g}\left(\mathbf{W} / \mathbf{m}^{2}\right)$ & $\mathbf{T r m}\left({ }^{\circ} \mathbf{C}\right)$ & $\mathbf{T a}\left({ }^{\circ} \mathbf{C}\right)$ & $\mathbf{U R}(\boldsymbol{\%})$ & $\mathbf{v}(\mathbf{m} / \mathbf{s})$ & $\mathbf{I g}\left(\mathbf{W} / \mathbf{m}^{2}\right)$ & $\mathbf{T r m}\left({ }^{\circ} \mathbf{C}\right)$ \\
\hline $10 \mathrm{~h} 00$ & 22,9 & 59 & 1,0 & 615 & 44,3 & 24,0 & 61 & 2,3 & 524 & 50,9 \\
$11 \mathrm{~h} 00$ & 25,0 & 51 & 1,0 & 832 & 52,6 & 26,1 & 52 & 2,6 & 860 & 57 \\
$12 \mathrm{~h} 00$ & 26,5 & 47 & 1,1 & 720 & 53,2 & 27,5 & 47 & 2,4 & 969 & 57,2 \\
$13 \mathrm{~h} 00$ & 27,2 & 45 & 1,3 & 78 & 32,7 & 28,7 & 41 & 2,2 & 1004 & 58,1 \\
$14 \mathrm{~h} 00$ & 28,4 & 42 & 1,2 & 99 & 33,9 & 30,4 & 31 & 1,8 & 949 & 59,4 \\
$15 \mathrm{~h} 00$ & 28,8 & 41 & 1,0 & 119 & 34,1 & 31,4 & 26 & 1,4 & 822 & 58,4 \\
\hline Média & 26,5 & 48 & 1,1 & 410 & 41,8 & 28 & 43 & 2,1 & 855 & 56,8 \\
\hline
\end{tabular}


No modelo da Sete de Setembro, o ponto SS1 corresponde ao ponto de monitoramento. Para uma análise mais ampla foram adicionados os pontos SS2, SS3 e SS4. No modelo da Linha Verde, note que o ponto LV1 corresponde ao local de medição das variáveis climáticas, sendo adicionados os pontos LV2 e LV3. Na Figura 4, a cor cinza corresponde às áreas construídas, a cor verde-escura às árvores e a cor verde-clara às superfícies gramadas.

Inicialmente, os primeiros testes com os modelos da Sete de Setembro e da Linha Verde foram realizados a partir dos valores médios diários de velocidade e direção do vento, como também de temperatura e de umidade relativa do ar. Em relação à umidade específica do ar a $2.500 \mathrm{~m}$ de altura, faz-se a ressalva de que no site de sondagens atmosféricas da Universidade de Wyoming não constam dados relativos aos meses de janeiro até maio de 2012 para a cidade de Curitiba. Para contornar essa situação, foram calculadas médias aritméticas para o mês de março dos anos de 2011 e 2013 e depois uma média final.

Nos testes iniciais, tanto na Sete de Setembro como na Linha Verde, os dados preditos apontaram valores de Ta no período analisado acima daqueles medidos; sendo necessário um valor de entrada mais baixo do que o valor médio diário. Optou-se, então, por utilizar o dado horário de Ta às 0h00; para as outras variáveis climáticas ficaram mantidas as médias diárias (Tabela 3).

A função solar adjust refere-se ao ajuste do cálculo para a radiação de onda curta, variando a partir de $50 \%$ até $150 \%$ do valor padrão calculado pelo
ENVI-met, sendo utilizado o valor de 1,2. Foi considerado céu claro, sem nuvens. Para as condições laterais do modelo, utilizou-se a opção forced. As outras opções de configuração foram mantidas originais. Foram descartadas as 33 primeiras horas de simulação.

As comparações dos resultados (etapa de validação) são apresentadas na Figura 5.

Conforme a Tabela 4, na Sete de Setembro a estimativa de erro médio quadrático foi de $0,55^{\circ} \mathrm{C}$, e o índice de concordância de Wilmott foi de 0,98 . No entanto, o teste $\mathrm{t}$ mostrou que há diferença significativa (valor $\mathrm{p}<0,05$ ) entre os valores de Ta preditos e medidos para aquela localidade. É provável que esse fato decorra das diferenças entre Ta medida e predita no horário das 11 h00 e 12h00. Na Linha Verde, a estimativa de erro médio quadrático foi de $0,40^{\circ} \mathrm{C}$, e o índice de concordância de Wilmott foi de 0,99; valores considerados satisfatórios. $\mathrm{O}$ teste $\mathrm{t}$ mostra que não há diferença significativa entre os valores de Ta preditos e medidos para um intervalo de $95 \%$ de confiança.

Especificamente na Sete de Setembro ressalta-se que, principalmente nas duas primeiras horas de medição (10h00 e 11h00), a Trm predita apresentou valores demasiadamente altos comparativamente aos valores medidos (Tabela 5), fator que refletiria diretamente na determinação das diferenças entre os índices de conforto medidos e simulados. Dessa forma, optou-se por considerar nos cenários simulados da Sete de Setembro apenas o recorte horário das $12 \mathrm{~h} 00$ até às $15 \mathrm{~h} 00$.

\section{Figura 4 - Modelos finalizados}

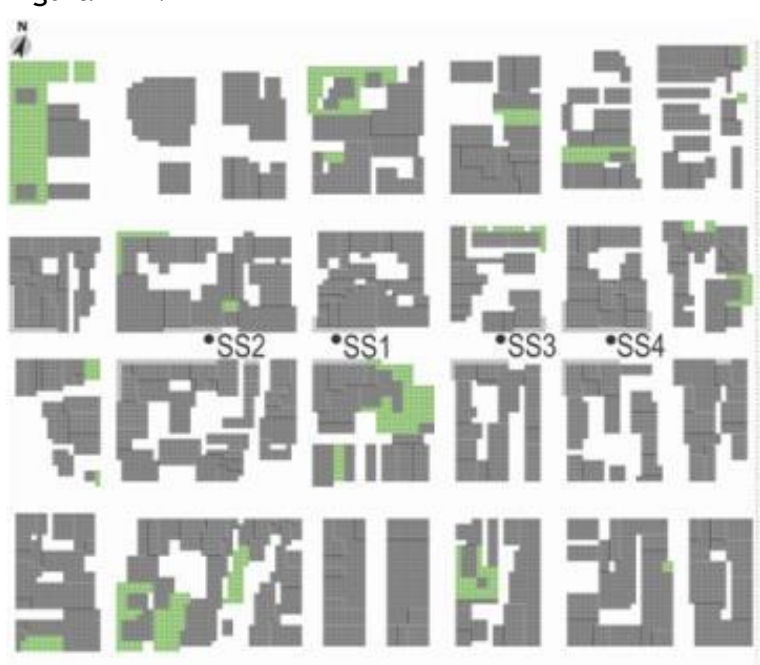

(a) Sete de Setembro

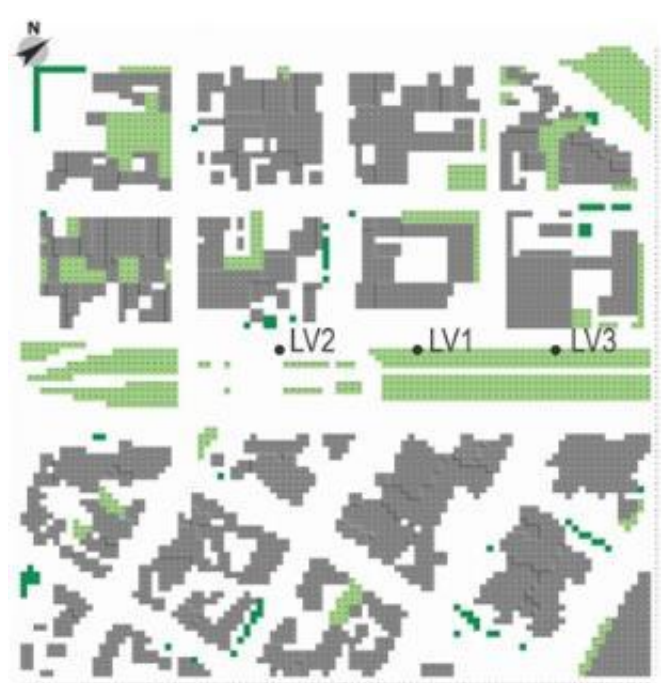

(B) Linha Verde

360 Minella, F. C. O.; Krüger, E. L. 
Tabela 3 - Configuração do modelo da Linha Verde e Sete de Setembro - dia medido

\begin{tabular}{l|c|c|c}
\hline \multicolumn{1}{c|}{ Configuração } & Sete de Setembro & Linha Verde & Referência \\
\hline Data & $10 / 3 / 2012$ & $7 / 3 / 2012$ & Dia medido \\
Início da simulação & $00: 00: 00$ & $00: 00: 00$ & Atmosfera neutra \\
Velocidade do vento (m/s) & 1,7 & 2,2 & Média diária \\
Direção do vento (graus) & 110 & 68 & Média diária \\
Comprimento de rugosidade & 0,1 & 0,1 & Valor estipulado \\
Temperatura do ar $(\mathrm{K})$ & 291 & 291,7 & Dado às 0h00 \\
Umidade especifica a $2.500 \mathrm{~m}(\mathrm{~g} / \mathrm{kg})$ & 9 & 9 & Valor calculado \\
Umidade relativa do ar $(\%)$ & 64 & 64 & Média diária \\
\hline
\end{tabular}

Figura 5 - Comparações entre a Ta medida e simulada

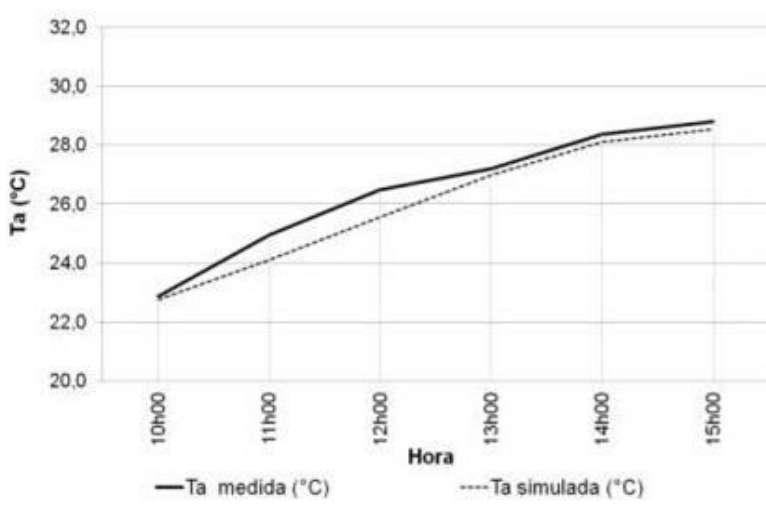

(a) Sete de Setembro

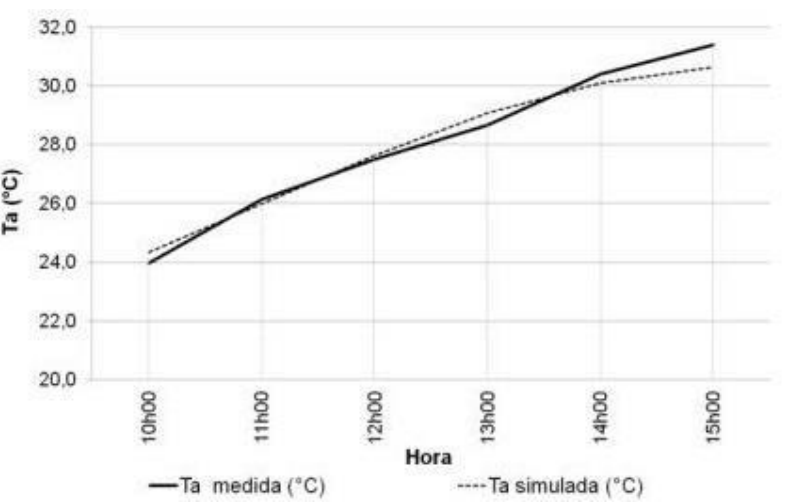

(b) Linha Verde

Tabela 4 - Resumo estatístico do modelo da Linha Verde e Sete de Setembro, considerando a Ta medida e predita como referência

\begin{tabular}{l|c|c}
\hline \multicolumn{1}{c|}{ Resumo Estatístico } & Sete de Setembro & Linha Verde \\
\hline erro médio (medida-predita) $\left({ }^{\circ} \mathrm{C}\right)$ & 0,44 & 0,05 \\
desvio padrão da Ta medida $\left({ }^{\circ} \mathrm{C}\right)$ & 2,23 & 2,74 \\
desvio padrão da Ta simulada $\left({ }^{\circ} \mathrm{C}\right)$ & 2,29 & 2,46 \\
erro médio absoluto $\left({ }^{\circ} \mathrm{C}\right)$ & 0,44 & 0,35 \\
RMSE $\left({ }^{\circ} \mathrm{C}\right)$ & 0,55 & 0,40 \\
índice de concordância de Wilmott (adimensional) & 0,98 & 0,99 \\
teste t-Student (adimensional) & 0,03 & 0,78 \\
\hline
\end{tabular}

Tabela 5 - Comparação horária entre os valores de Trm medida e predita na Sete de Setembro

\begin{tabular}{c|c|c|c}
\hline Hora & Trm medida $\left({ }^{\circ} \mathbf{C}\right)$ & Trm predita $\left({ }^{\circ} \mathbf{C}\right)$ & $\operatorname{Trm}_{\text {predita - medida }}\left({ }^{\circ} \mathbf{C}\right)$ \\
\hline 10h00 & 44,3 & 76,8 & 32,4 \\
1 1h00 & 52,6 & 75,6 & 23,0 \\
$12 \mathrm{~h} 00$ & 53,2 & 36,3 & $-16,8$ \\
$13 \mathrm{~h} 00$ & 32,7 & 35,3 & 2,6 \\
$14 \mathrm{~h} 00$ & 33,9 & 35,2 & 1,3 \\
$15 \mathrm{~h} 00$ & 34,1 & 34,5 & 0,4 \\
\hline
\end{tabular}

Na Tabela 6 constam os valores médios medidos e preditos dos pontos monitorados na Sete de Setembro (período das $12 \mathrm{~h} 00$ até às $15 \mathrm{~h} 00$ ) e na Linha Verde (período das $10 \mathrm{~h} 00$ até às $15 \mathrm{~h} 00$ ), considerando as variáveis climáticas monitoradas e o índice de conforto térmico UTCI.

\section{Simulações com o dia típico de verão}

A Figura 6 corresponde à carta solar sobreposta à foto olho de peixe para a Sete de Setembro e para a Linha Verde. O traçado na cor laranja corresponde aos dias em que os pontos foram monitorados (dia 10/3/2012 na Sete de Setembro e dia 7/3/2012 na Linha Verde). 
Conforme pode ser observado, durante o período das 11 h00 até às $18 \mathrm{~h} 00$ do dia 10/3/2012, o ponto na Sete de Setembro estava sujeito ao sombreamento das edificações do entorno. Dessa forma, optou-se por concentrar as simulações dos cenários futuros não para um dia específico, mas para um dia típico de projeto, uma vez que haveria menos sombreamento no cânion urbano da Sete de Setembro, propiciando uma melhor avaliação da condição de conforto térmico. $\mathrm{O}$ traçado na cor vermelha corresponde ao dia típico de projeto (28/1/2012).
Para a simulação com o dia típico de projeto (Tabela 7), foram utilizados na configuração dos dados de entrada do ENVI-met os parâmetros que haviam sido testados conforme a coluna de "referência" da Tabela 3.

\section{Avaliação dos cenários propostos}

A Tabela 8 e a Tabela 9 contêm dados de Ta e categoria de estresse térmico do cenário atual, bem como os dados do cenário proposto, para um dia típico de projeto.

Tabela 6 - Valores médios medidos e preditos: Sete de Setembro e Linha Verde

\begin{tabular}{|c|c|c|c|c|c|c|c|c|}
\hline Ponto & Média & $\begin{array}{c}\mathbf{T a} \\
\left({ }^{\circ} \mathbf{C}\right) \\
\end{array}$ & $\begin{array}{l}\text { Trm } \\
\left({ }^{\circ} \mathbf{C}\right)\end{array}$ & $\begin{array}{c}\text { Ig } \\
\left(\mathrm{W} / \mathbf{m}^{2}\right)\end{array}$ & $\begin{array}{l}\text { UR } \\
(\%) \\
\end{array}$ & $\begin{array}{c}\mathbf{v} \\
(\mathbf{m} / \mathbf{s})\end{array}$ & $\begin{array}{c}\text { UTCI } \\
\left({ }^{\circ} \mathbf{C}\right) \\
\end{array}$ & $\begin{array}{l}\text { Categoria de estresse } \\
\text { térmico ao calor }\end{array}$ \\
\hline \multirow{2}{*}{ Sete de Setembro } & medida & 26,5 & 41,8 & 410 & 48 & 1,1 & 29,3 & moderado \\
\hline & predita & 26,0 & 49,0 & 436 & 44 & 0,7 & 28,7 & moderado \\
\hline \multirow{2}{*}{ Linha Verde } & medida & 28,0 & 56,8 & 855 & 43 & 2,1 & 32,2 & forte \\
\hline & predita & 28,0 & 58,0 & 996 & 45 & 1,7 & 33,3 & forte \\
\hline
\end{tabular}

Figura 6 - Foto olho de peixe e traçado solar para: (a) Sete de Setembro e (b) Linha Verde

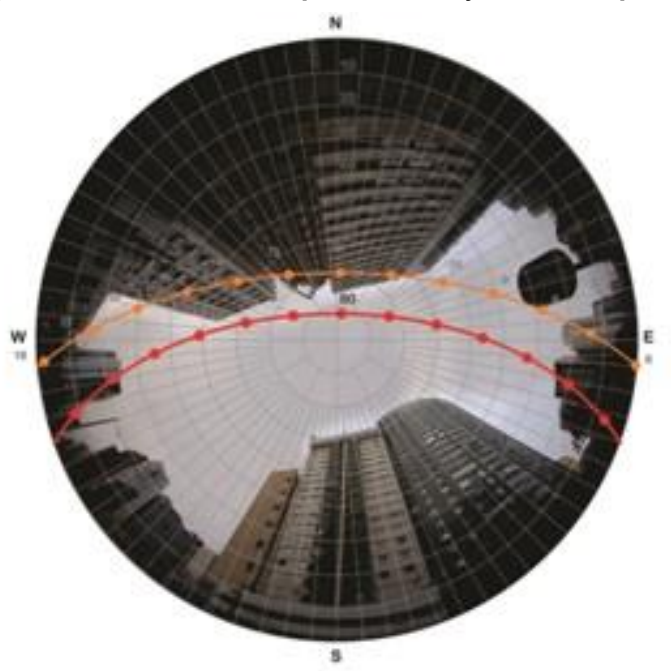

(a) Sete de Setembro

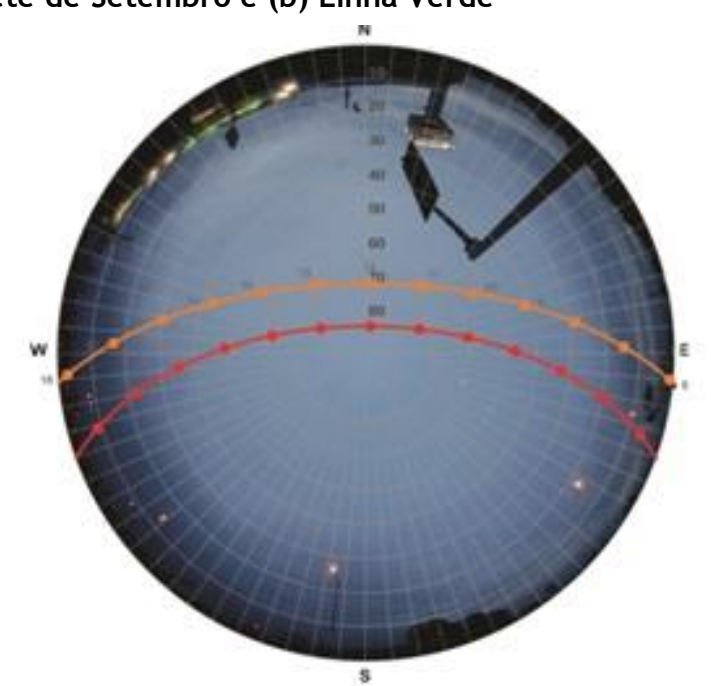

(b) Linha Verde

Tabela 7 - Configuração do modelo da Linha Verde e Sete de Setembro - dia típico de projeto

\begin{tabular}{l|c|c}
\hline \multicolumn{1}{c|}{ Configuração } & $\begin{array}{c}\text { Sete de Setembro e } \\
\text { Linha Verde }\end{array}$ & Referência \\
\hline Data & $28 / 1 / 2012$ & Dia típico de projeto nível 1\% \\
Início da simulação & $00: 00: 00$ & Atmosfera neutra \\
Velocidade do vento (m/s) & 3,2 & Média diária \\
Direção do vento (graus) & 90 & Média diária \\
Comprimento de rugosidade & 0,1 & Valor estipulado \\
Temperatura do ar $(\mathrm{K})$ & 293,6 & Dado às 0h00 \\
Umidade Especifica a $2500 \mathrm{~m}(\mathrm{~g} / \mathrm{kg})$ & 9 & Valor calculado \\
Umidade Relativa do ar $(\%)$ & 80 & Média diária \\
\hline
\end{tabular}

362 Minella, F. C. O.; Krüger, E. L. 
Tabela 8 - Sete de Setembro: avaliação dos cenários atual (antes) e proposto (depois)

\begin{tabular}{|c|c|c|c|c|c|c|c|c|c|c|c|c|}
\hline \multirow{3}{*}{ Hora } & \multicolumn{3}{|c|}{ SS1 } & \multicolumn{3}{|c|}{ SS2 } & \multicolumn{3}{|c|}{ SS3 } & \multicolumn{3}{|c|}{ SS4 } \\
\hline & \multirow{2}{*}{$\begin{array}{c}\text { Ta } \\
\left({ }^{\circ} \mathbf{C}\right)\end{array}$} & \multirow{2}{*}{$\begin{array}{c}\begin{array}{c}\text { Ta } \\
\left({ }^{\circ} \mathbf{C}\right)\end{array} \\
\text { depois }\end{array}$} & \multirow{2}{*}{$\begin{array}{l}\text { Dif } \\
\left({ }^{\circ} \mathbf{C}\right)\end{array}$} & $\begin{array}{c}\mathbf{T a} \\
\left({ }^{\circ} \mathbf{C}\right)\end{array}$ & $\begin{array}{c}\text { Ta } \\
\left({ }^{\circ} \mathbf{C}\right) \\
\end{array}$ & \multirow{2}{*}{$\begin{array}{l}\text { Dif } \\
\left({ }^{\circ} \mathbf{C}\right)\end{array}$} & \multirow{2}{*}{\begin{tabular}{|c|} 
Ta \\
$\left({ }^{\circ} \mathbf{C}\right)$
\end{tabular}} & \multirow{2}{*}{$\begin{array}{c}\text { Ta } \\
\left({ }^{\circ} \mathbf{C}\right) \\
\text { depoi } \\
\text { s } \\
\end{array}$} & \multirow{2}{*}{$\begin{array}{l}\text { Dif } \\
\left({ }^{\circ} \mathbf{C}\right)\end{array}$} & $\begin{array}{c}\mathbf{T a} \\
\left({ }^{\circ} \mathbf{C}\right)\end{array}$ & $\begin{array}{c}\mathbf{T a} \\
\left({ }^{\circ} \mathbf{C}\right)\end{array}$ & \multirow{2}{*}{$\begin{array}{c}\text { Dif } \\
\left({ }^{\circ} \mathbf{C}\right)\end{array}$} \\
\hline & & & & antes & & & & & & & & \\
\hline $\mathrm{FVC}$ & 0,47 & 0,00 & - & 0,49 & 0,02 & - & 0,55 & 0,01 & - & 0,55 & 0,00 & - \\
\hline $12 \mathrm{~h} 00$ & 27,9 & 27,5 & 0,5 & 27,6 & 27,2 & 0,4 & 28,6 & 28 & 0,6 & 29,5 & 28,6 & 0,9 \\
\hline $13 \mathrm{~h} 00$ & 29,4 & 28,8 & 0,6 & 29,1 & 28,6 & 0,5 & 30,1 & 29,4 & 0,7 & 31,1 & 30,1 & 1 \\
\hline $14 \mathrm{~h} 00$ & 30,3 & 29,5 & 0,8 & 30 & 29,4 & 0,6 & 31 & 30,1 & 0,8 & 31,9 & 30,8 & 1,1 \\
\hline $15 \mathrm{~h} 00$ & 30,6 & 29,7 & 0,9 & 30,3 & 29,5 & 0,8 & 31,2 & 30,3 & 0,9 & 32,1 & 30,8 & 1,2 \\
\hline Média & 29,5 & 28,9 & 0,7 & 29,2 & 28,7 & 0,6 & 30,2 & 29,4 & $\mathbf{0 , 8}$ & 31,1 & 30,1 & 1,1 \\
\hline $\begin{array}{c}\text { UTCI } \\
\left({ }^{\circ} \mathrm{C}\right)\end{array}$ & 38,5 & 28,6 & 9,9 & 33,5 & 28,2 & 5,3 & 38,3 & 28,8 & 9,5 & 37 & 28,9 & 8,1 \\
\hline categoria & $\begin{array}{l}\text { Muito } \\
\text { forte }\end{array}$ & Mode & ado & Forte & Mode & ado & $\begin{array}{l}\text { Muito } \\
\text { forte }\end{array}$ & Mod & ado & Forte & Mod & do \\
\hline
\end{tabular}

Tabela 9 - Linha Verde: avaliação dos cenários atual (antes) e proposto (depois)

\begin{tabular}{|c|c|c|c|c|c|c|c|c|c|}
\hline \multirow{3}{*}{ Hora } & \multicolumn{3}{|c|}{ LV1 } & \multicolumn{3}{|c|}{ LV2 } & \multicolumn{3}{|c|}{ LV3 } \\
\hline & \multirow{2}{*}{$\begin{array}{c}\text { Ta } \\
\left({ }^{\circ} \mathbf{C}\right)\end{array}$} & \multirow{2}{*}{\begin{tabular}{|c|} 
Ta \\
$\left({ }^{\circ} \mathbf{C}\right)$
\end{tabular}} & \multirow{2}{*}{$\begin{array}{c}\text { Dif } \\
\left({ }^{\circ} \mathbf{C}\right)\end{array}$} & \multirow{2}{*}{$\begin{array}{c}\begin{array}{c}\text { Ta } \\
\left({ }^{\circ} \mathbf{C}\right)\end{array} \\
\text { antes }\end{array}$} & \multirow{2}{*}{$\begin{array}{c}\text { Ta } \\
\left({ }^{\circ} \mathbf{C}\right) \\
\text { depois } \\
\end{array}$} & \multirow{2}{*}{$\begin{array}{c}\text { Dif } \\
\left({ }^{\circ} \mathbf{C}\right)\end{array}$} & \multirow{2}{*}{\begin{tabular}{|c|} 
Ta \\
$\left({ }^{\circ} \mathbf{C}\right)$ \\
antes \\
\end{tabular}} & \multirow{2}{*}{$\begin{array}{c}\text { Ta } \\
\left({ }^{\circ} \mathbf{C}\right) \\
\text { depois } \\
\end{array}$} & \multirow{2}{*}{$\begin{array}{c}\text { Dif } \\
\left({ }^{\circ} \mathbf{C}\right)\end{array}$} \\
\hline & & & & & & & & & \\
\hline $\mathrm{FVC}$ & 0,97 & 0,13 & - & 0,97 & 0,63 & - & 0,97 & 0,13 & - \\
\hline 10h00 & 25,8 & 25,1 & 0,7 & 26,0 & 25,7 & 0,3 & 26,3 & 25,4 & 0,9 \\
\hline $11 \mathrm{~h} 00$ & 27,5 & 26,7 & 0,8 & 27,7 & 27,3 & 0,4 & 28,1 & 27,0 & 1,1 \\
\hline $12 \mathrm{~h} 00$ & 29,1 & 28,3 & 0,8 & 29,3 & 28,9 & 0,4 & 29,8 & 28,8 & 1,0 \\
\hline $13 \mathrm{~h} 00$ & 30,5 & 29,6 & 0,9 & 30,7 & 30,3 & 0,4 & 31,2 & 30,1 & 1,1 \\
\hline $14 \mathrm{~h} 00$ & 31,5 & 30,4 & 1,1 & 31,6 & 31,1 & 0,6 & 32,2 & 30,8 & 1,4 \\
\hline $15 \mathrm{~h} 00$ & 31,9 & 30,7 & 1,2 & 32,1 & 31,4 & 0,6 & 32,6 & 31,1 & 1,5 \\
\hline Média & 29,4 & 28,5 & 0,9 & 29,6 & 29,1 & 0,4 & 30,0 & 28,8 & 1,2 \\
\hline $\begin{array}{c}\text { UTCI } \\
\left({ }^{\circ} \mathrm{C}\right)\end{array}$ & 33,6 & 28,4 & 5,2 & 36,9 & 34,7 & 2,2 & 34,3 & 28,8 & 5,6 \\
\hline categoria & Forte & \multicolumn{2}{|c|}{ Moderado } & Forte & \multicolumn{2}{|c|}{ Forte } & Forte & \multicolumn{2}{|c|}{ Moderado } \\
\hline
\end{tabular}

Na Sete de Setembro, nota-se que o ponto SS2 apresentou a menor redução na Ta entre os pontos analisados, com $0,6^{\circ} \mathrm{C}$. O ponto com redução mais significativa foi o SS4, com média de $1,1^{\circ} \mathrm{C}$. Embora tenham ocorrido diferenças nas categorias de conforto entre os pontos no cenário atual (variação entre forte e muito forte estresse térmico ao calor), a partir da adição de área arborizada no cenário proposto a melhora máxima obtida foi "moderado estresse ao calor", conforme o índice UTCI.

A Figura 7 e a Figura 8 possibilitam a visualização do cenário atual e do cenário proposto às $15 \mathrm{~h} 00$, respectivamente. Nesse horário, apenas no recorte da Sete de Setembro o cenário proposto apresentou uma Ta $0,8^{\circ} \mathrm{C}$ inferior ao cenário atual.

Na Linha Verde, a maior média de Ta encontra-se no ponto $\mathrm{LV} 3$, com $30^{\circ} \mathrm{C}$. O ponto menos aquecido é o ponto LV1, com $29,4^{\circ} \mathrm{C}$. A categoria de estresse térmico para ambos os pontos é "forte estresse térmico ao calor". O ponto LV2 apresentou Ta média intermediária. No entanto, o valor do índice UTCI para esse ponto foi maior comparativamente aos outros dois. Isso decorre do fato de que LV2 apresenta maior valor de Trm, pois ele se encontra sobre superfície pavimentada, enquanto os outros dois pontos encontram-se sobre superfície originalmente gramada. No entanto, na categorização do índice, os três pontos encontram-se sob "forte estresse térmico".

A partir da inserção de arborização no cenário proposto, percebe-se que o ponto LV3, que possuía a maior Ta entre os três pontos, sofre maior redução, com média de $1,2^{\circ} \mathrm{C}$. No ponto $\mathrm{LV} 1$, a Ta é reduzida em média $0,9^{\circ} \mathrm{C}$. Nesses pontos, a categoria "muito forte estresse térmico" passa para "moderado estresse térmico ao calor". No ponto LV2, a redução na Ta é menos significativa, pois ele não está diretamente sob a copa das árvores. Nesse ponto, a redução média de $2,2^{\circ} \mathrm{C}$ no índice UTCI não é suficiente para uma melhora na 
condição de conforto, o que faz com que o ponto permaneça em forte estresse térmico ao calor.

A Figura 9 e a Figura 10 correspondem à distribuição horizontal da Ta nos cenários atual e proposto, respectivamente, às 15 h00, horário no qual houve redução mais significativa da Ta. No cenário proposto, nota-se que as áreas arborizadas contribuem para um resfriamento da área como um todo, mas principalmente nos canteiros, local de implantação da vegetação arbórea. Nesse horário, no cenário proposto a Ta na via era $0,8^{\circ} \mathrm{C}$ menor que no cenário atual.

Figura 7 - Sete de Setembro: mapa térmico do cenário atual, às $15 \mathrm{~h} 00$

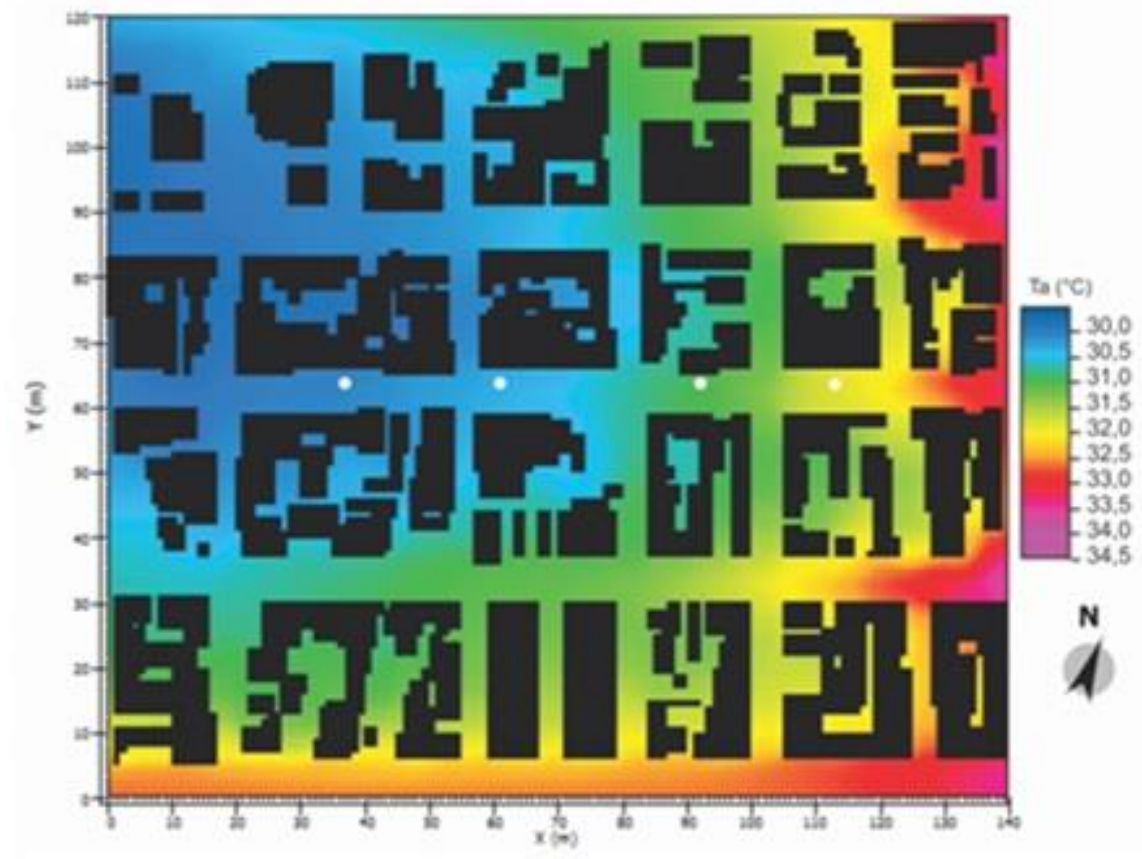

Figura 8 - Sete de Setembro: mapa térmico do cenário proposto, às 15 h00

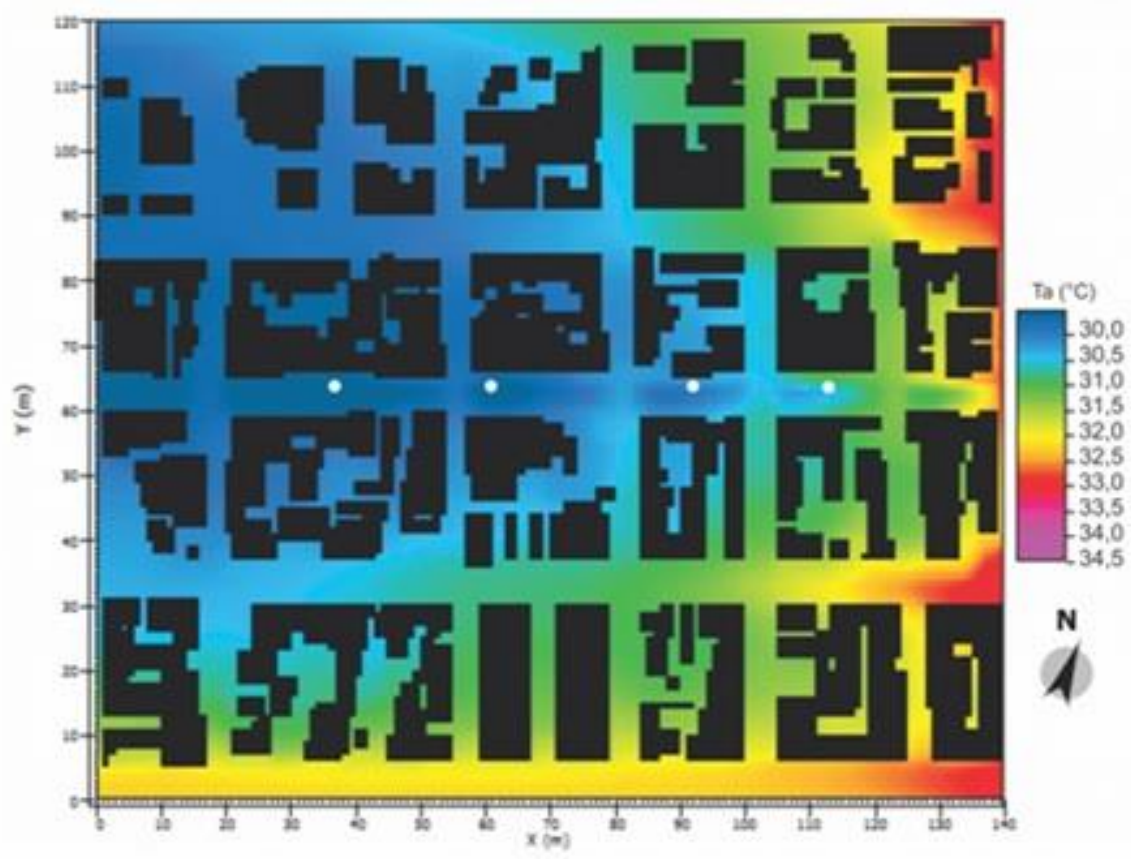

364 Minella, F. C. O.; Krüger, E. L. 
Figura 9 - Linha Verde: mapa térmico do cenário atual, às $15 \mathrm{~h} 00$

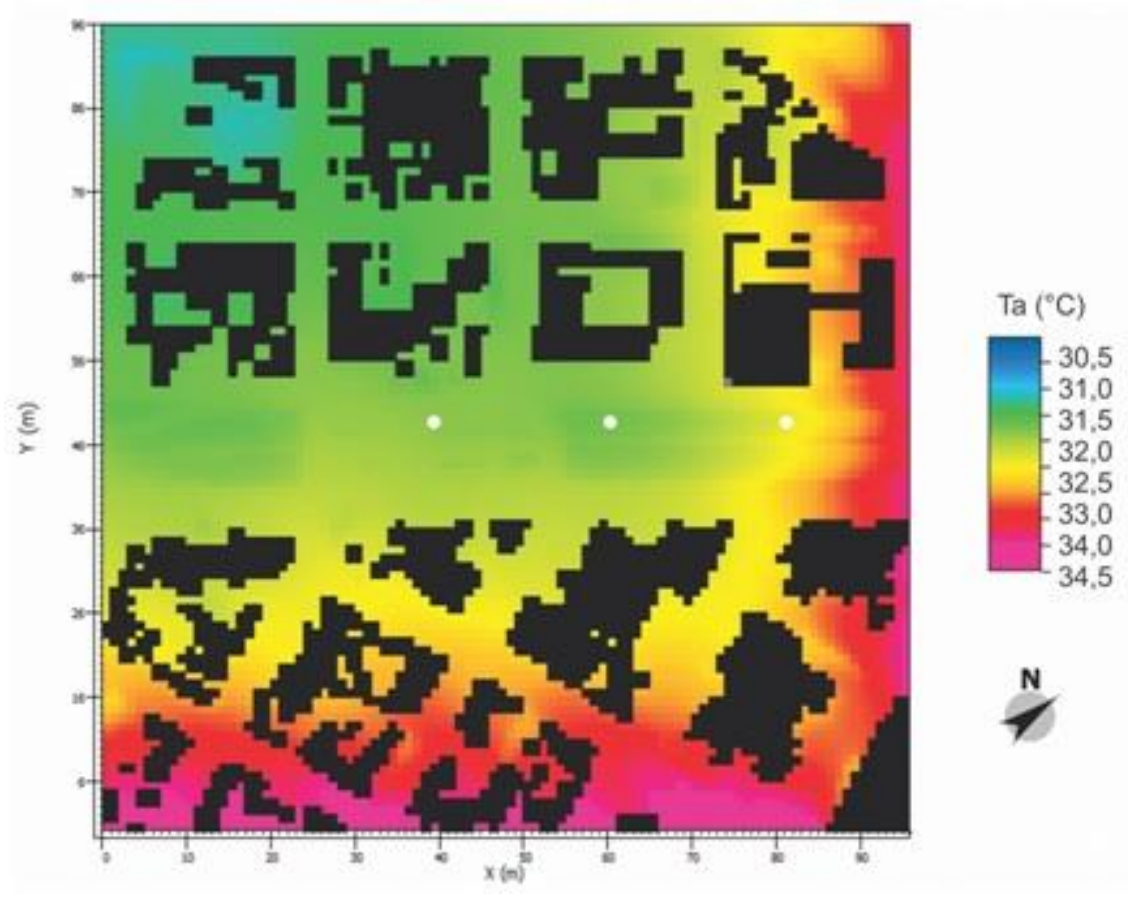

Figura 10 - Linha Verde: mapa térmico do cenário proposto, às $15 \mathrm{~h} 00$

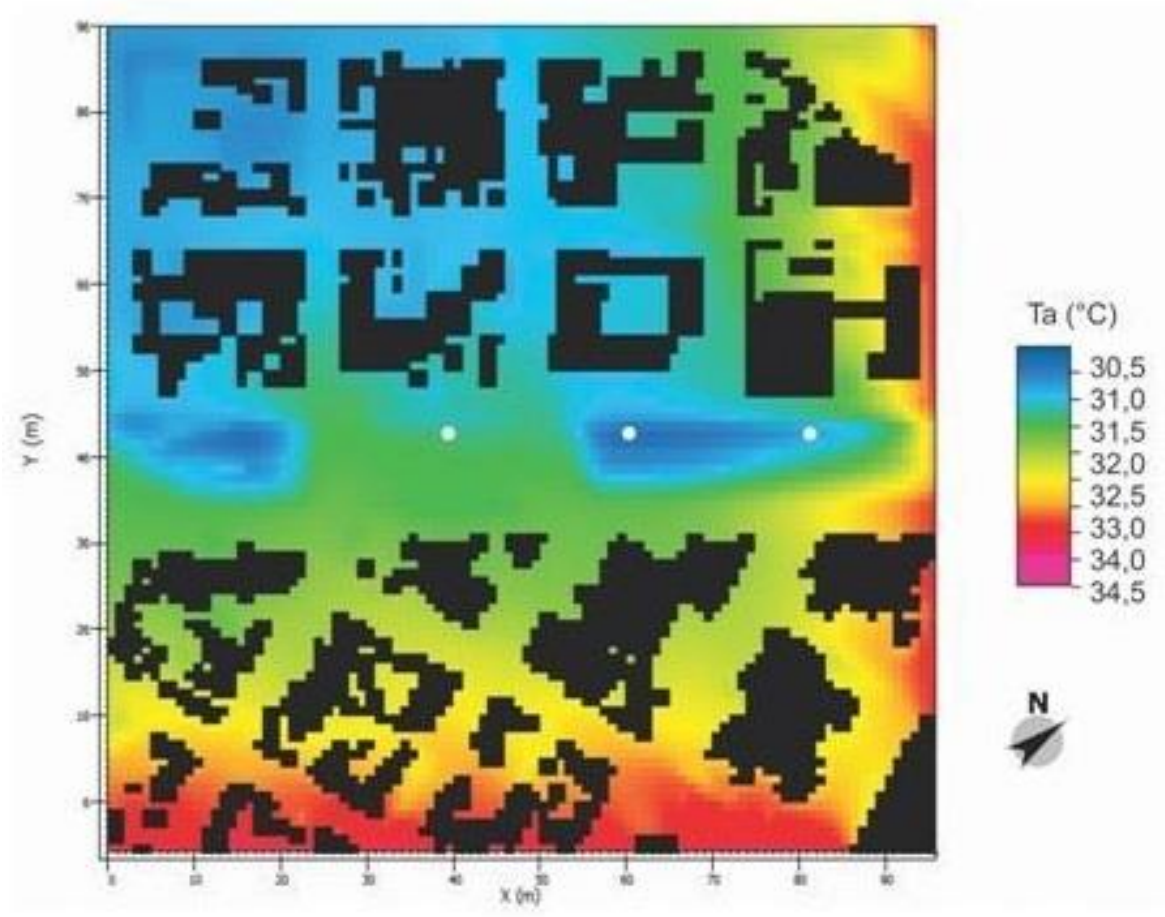

\section{Proposição do índice "fração vegetada"}

Para que fosse possível identificar a área de cobertura vegetal (coeficiente de vegetação) necessária para amenizar a temperatura do ar, foi desenvolvido um índice que relaciona aumento de cobertura vegetal e áreas construídas em termos de redução da temperatura do ar (Ta), denominado de "fração vegetada".

A primeira etapa consistiu em dimensionar os recortes dentro de cada modelo da Sete de Setembro e da Linha Verde. Procurou-se estipular uma área que tivesse um tamanho compatível para 
cada recorte, concluindo-se que o tamanho ideal de cada recorte era próximo de 4 ha (Tabela 10).

O número de recortes coincide com o número de pontos alocados em cada modelo e a nomenclatura dos pontos serviram para identificar cada recorte. Assim, na Sete de Setembro foram considerados quatro recortes e na Linha Verde três recortes, totalizando sete recortes representados pelos retângulos na Figura 11.

Ressalta-se que as reduções na temperatura do ar relacionadas ao índice desenvolvido se referem à Ta média em cada área de recorte, e não à Ta registrada no ponto. Para cada recorte, foram considerados dados relativos ao aumento de cobertura vegetal e à densidade construída.

O cálculo do aumento da cobertura vegetal (em $\mathrm{m}^{2}$ ) foi realizado com base na projeção horizontal das grades com árvores, desconsiderando a vegetação já existente. Para isso, foi contado o número de grades correspondente às áreas verdes dentro de cada recorte. Posteriormente, o número de grades foi multiplicado pela área de cada grade.

A área construída foi calculada pela soma da projeção horizontal das edificações e as quatro superfícies de parede de acordo com as alturas individuais de cada edifício, sendo assim denominada de "área construída 3D". Os dois parâmetros resultaram no índice "fração vegetada" FV (FV = cobertura vegetal / área construída 3D) para cada recorte, o qual foi então correlacionado a alterações de temperatura ambiente (Equação 5) segundo os resultados das simulações (Tabela 11).

Taalterações $=$ coef. $. \mathrm{a}^{*} \mathrm{FV}+$ coef.b

Eq. 5

Tabela 10 - Cálculo dos recortes na Sete de Setembro e Linha Verde

\begin{tabular}{|c|c|c|c|c|c|}
\hline Recortes & Eixo & Numero de grade & $\begin{array}{l}\text { Tamanho da célula } \\
\text { de grade }(\mathrm{m})\end{array}$ & Total (m) & $\begin{array}{c}\text { Área de análise } \\
\text { (ha) }\end{array}$ \\
\hline \multirow{2}{*}{ SS1 } & $\mathrm{x}$ & 27 & 6 & 162 & \multirow{2}{*}{4.0} \\
\hline & $\mathrm{y}$ & 41 & 6 & 246 & \\
\hline \multirow{2}{*}{$\mathrm{SS} 2$} & $\mathrm{x}$ & 34 & 6 & 204 & \multirow{2}{*}{4,0} \\
\hline & $\mathrm{y}$ & 33 & 6 & 198 & \\
\hline \multirow{2}{*}{ SS3 } & $\mathrm{x}$ & 21 & 6 & 126 & \multirow{2}{*}{4,1} \\
\hline & $\mathrm{y}$ & 53 & 6 & 318 & \\
\hline \multirow{2}{*}{ SS4 } & $\mathrm{x}$ & 21 & 6 & 126 & \multirow{2}{*}{4,0} \\
\hline & $\mathrm{y}$ & 53 & 6 & 318 & \\
\hline \multirow{2}{*}{ LV1 } & $\mathrm{x}$ & 25 & 6 & 150 & \multirow{2}{*}{4,0} \\
\hline & $\mathrm{y}$ & 44 & 6 & 264 & \\
\hline \multirow{2}{*}{ LV2 } & $\mathrm{x}$ & 22 & 6 & 132 & \multirow{2}{*}{4,0} \\
\hline & $\mathrm{y}$ & 50 & 6 & 300 & \\
\hline \multirow{2}{*}{ LV3 } & $\mathrm{x}$ & 22 & 6 & 132 & \multirow{2}{*}{4,0} \\
\hline & $\mathrm{y}$ & 50 & 6 & 300 & \\
\hline
\end{tabular}

Figura 11 - Recortes para cada modelo: (a) Sete de Setembro e (b) Linha Verde

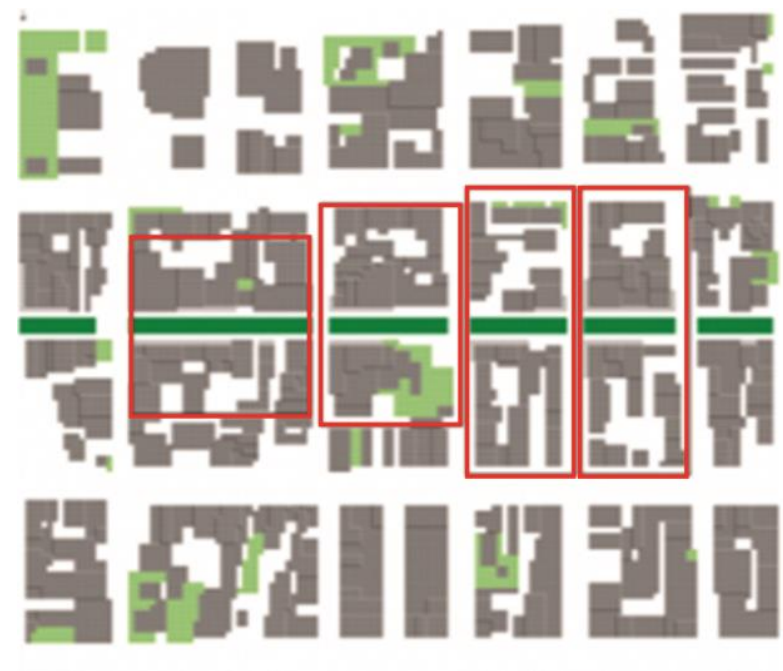

(a) Sete de Setembro

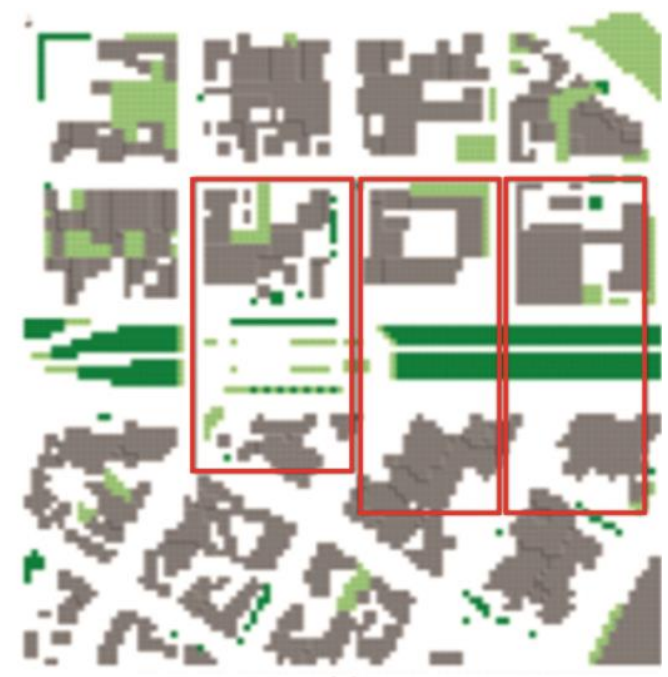

(b) Linha Verde

366 Minella, F. C. O.; Krüger, E. L. 
Tabela 11 - Resultados de alterações de temperatura ambiente em função da fração vegetada

\begin{tabular}{c|c|c|c|c|c}
\hline Recorte & $\begin{array}{c}\text { Cobertura } \\
\text { vegetal }\left(\mathbf{m}^{\mathbf{2}}\right)\end{array}$ & $\begin{array}{c}\text { Área construída } \\
\left(\mathbf{m}^{\mathbf{2}}\right)\end{array}$ & $\begin{array}{c}\text { Área construída } \\
\mathbf{3 D}\left(\mathbf{m}^{\mathbf{2}}\right)\end{array}$ & $\begin{array}{c}\text { Fração vegetada } \\
\mathbf{- ~ F V ~}\end{array}$ & $\begin{array}{c}\text { Redução média } \\
\mathbf{d e ~} \mathbf{T a}\left({ }^{\circ} \mathbf{C}\right)\end{array}$ \\
\hline SS1 & 2376 & 11412 & 41119 & 0,06 & 0,24 \\
SS2 & 3672 & 25668 & 63687 & 0,06 & 0,31 \\
SS3 & 1944 & 24696 & 66228 & 0,03 & 0,34 \\
SS4 & 1836 & 18864 & 56011 & 0,03 & 0,41 \\
LV1 & 4140 & 12996 & 16245 & 0,25 & 0,58 \\
LV2 & 828 & 9288 & 12052 & 0,07 & 0,42 \\
LV3 & 5544 & 12780 & 15598 & 0,36 & 0,63 \\
\hline
\end{tabular}

O índice "fração vegetada" pode explicar as mudanças na temperatura ambiente, considerando a situação de verão, em $78 \%$ (R-quadrado $=0,89$ ). A partir da equação de regressão obtida (Taalterações $=0,9743 * \mathrm{FV}+0,2994), \quad$ a quantidade de vegetação requerida para a redução em $1^{\circ} \mathrm{C}$ da temperatura do ar pode ser estimada, mantendo-se a área construída inalterada.

Os resultados sugerem que, a fim de alcançar uma queda de $1^{\circ} \mathrm{C}$ na Ta por meio do aumento da cobertura vegetal, é necessária a adição significativa de áreas verdes, sendo isso às vezes inviável. A área de vegetação necessária para compensar um aumento da temperatura ambiente em $1^{\circ} \mathrm{C}$ em áreas com urbanização consolidada, por exemplo, ultrapassaria o espaço físico disponível (vide pontos SS2, SS3, SS4), sendo considerado inclusive o interior das quadras e não somente a arborização viária. De fato, extraindose uma relação direta entre o cobrimento vegetal e a densidade de área construída 3D (área construída 3D/área total), um limite de 0,85 é encontrado. A densidade construída (projetada ou "2D") não mostrou ser indicador tão relevante quanto a densidade de área construída 3D. Se tomarmos SS1 como exemplo, com uma densidade construída inferior a LV1, LV2 e LV3, o cobrimento vegetal necessário ultrapassaria o limite físico da área para tanto (Tabela 12).

\section{Discussão}

O índice mostra que, para as áreas de estudo selecionadas em Curitiba, seria necessário um aumento de $72 \%$ de cobertura vegetal para a redução de $1{ }^{\circ} \mathrm{C}$ na temperatura do ar. A quantidade substancial de área verde necessária para uma diminuição relativamente pequena da temperatura do ar indica o potencial de resfriamento requerido para mitigar o aquecimento de áreas urbanas.

Para um dia típico, considerando o período diurno e a situação de verão, a inserção de árvores de copa densa no centro das avenidas Sete de Setembro e Linha Verde, formando um parque linear, não é capaz de alcançar conforto térmico local. No entanto, é importante considerar que o estresse térmico pode ser reduzido em até duas categorias, aproximando-se da neutralidade térmica.

$\mathrm{Na}$ Sete de Setembro, para todo o perímetro modelado, a partir do cenário proposto e com inserção de área arborizada correspondendo a $3,6 \%$, a Ta sofreria uma redução de $0,2^{\circ} \mathrm{C}$. Tal impacto se aproxima ao alcançado por $\mathrm{Ng}$ et al. (2012), que verificaram uma diminuição de $0,4^{\circ} \mathrm{C}$ na temperatura ambiente após a inserção de árvores cobrindo $16 \%$ da área de estudo.

Schmitz (2014) simulou a partir do modelo as condições climáticas e de conforto térmico de modelos de ocupação em três quadras no setor estrutural nos anos de 2036 e 2061, o que possibilitou a avaliação de diferentes diretrizes de desenho urbano. De modo a verificar a contribuição de áreas verdes no microclima foram considerados modelos que consideraram a intensificação da arborização, áreas gramíneas e telhados verdes, em estrátegias isoladas e combinadas. Os resultados mais expressivos ocorreram nos cenários para o ano 2061 com intensificação de arborização com árvores de grande porte e $20 \mathrm{~m}$ de altura, com redução de até $4^{\circ} \mathrm{C}$ na temperatura equivalente (UTCI).

$\mathrm{Na}$ Linha Verde, considerando toda a área modelada, observa-se uma redução de $0,5^{\circ} \mathrm{C}$ na Ta média a partir da introdução de $4,6 \%$ de área arborizada. Esse resultado se assemelha ao encontrado por Chen e Wong (2006), para Singapura $\left(1^{\circ} 22^{\prime} 0^{\prime \prime} \mathrm{N}, 103^{\circ} 48^{\prime} 0^{\prime \prime} \mathrm{E}\right)$, a partir de simulações com ENVI-met, a partir do efeito da retirada de um parque urbano na temperatura do ar para o entorno.

De forma pontual, as reduções mais significativas (média de $1,1^{\circ} \mathrm{C}$ no ponto SS4 e de $1,2^{\circ} \mathrm{C}$ no ponto LV3) estão próximas às encontradas por Spangenberg et al. (2008) e Minella, Honjo e Krüger (2012) na comparação, via simulação com o ENVI-met, entre cenários sem vegetação e com árvores de copa densa para a cidade de São Paulo. 
Tabela 12 - Estimativa para cobertura vegetal requerida para uma diminuição de $1^{\circ} \mathrm{C}$ na temperatura do ar (média para uma área urbana de $4 \mathrm{ha}$ )

\begin{tabular}{c|c|c|c|c|c}
\hline Recorte & FV requerida & $\begin{array}{c}\text { Cobertura } \\
\text { vegetal } \\
\text { requerida }\left(\mathbf{m}^{2}\right)\end{array}$ & $\begin{array}{c}\text { Cobertura vegetal } \\
\text { requerida para uma } \\
\text { área de 4 ha } \mathbf{\%})\end{array}$ & $\begin{array}{c}\text { Densidade } \\
\text { construída } \\
\text { projeção 2D) }\end{array}$ & $\begin{array}{c}\text { Densidade de } \\
\text { área construída } \\
\text { 3D }\end{array}$ \\
\hline SS1 & $72 \%$ & 29568 & 74 & 0,29 & 1,03 \\
SS2 & $\mathbf{7 2 \%}$ & $\mathbf{4 5 7 9 6}$ & $\mathbf{1 1 3}$ & $\mathbf{0 , 6 4}$ & $\mathbf{1 , 5 8}$ \\
SS3 & $\mathbf{7 2 \%}$ & $\mathbf{4 7 6 2 3}$ & $\mathbf{1 1 9}$ & $\mathbf{0 , 6 2}$ & $\mathbf{1 , 6 5}$ \\
SS4 & $\mathbf{7 2 \%}$ & $\mathbf{4 0 2 7 6}$ & $\mathbf{1 0 1}$ & 0,37 & $\mathbf{1 , 4 0}$ \\
LV1 & $72 \%$ & 11682 & 29 & 0,23 & 0,41 \\
LV2 & $72 \%$ & 8666 & 22 & 0,32 & 0,39 \\
LV3 & $72 \%$ & 11216 & 28 & & \\
\hline
\end{tabular}

No entanto, a comparação entre diferentes estudos requer cuidado, pois diferentes metodologias são aplicadas (principalmente no que se refere à simulação de cenários urbanos e seus microclimas), e isso pode influenciar os resultados finais, e pelas próprias limitações do programa de simulação utilizado.

A importância da morfologia urbana, representada na pesquisa pelo fator de visão do céu, na formação do campo térmico fica evidente quando consideradas apenas as vias nas quais as interferências foram aplicadas diretamente, pois o mesmo resultado foi alcançado (redução de $0,6^{\circ} \mathrm{C}$ na Ta) para uma diferença expressiva de área verde adicionada $(27,5 \%$ na Linha Verde - local aberto, com maior valor de FVC, contra $85,3 \%$ na Sete de Setembro - cânion urbano). Ressalta-se que a adição de área verde foi disposta de modo a configurar corredores verdes. Porém, resultados mais satisfatórios poderiam ser obtidos se a vegetação fosse distribuída ao longo da malha urbana e não concentrada em apenas uma única via. Nesse sentido, ressalta-se que a forma de distribuição da vegetação (WONG; STEVE, 2008) e a densidade da copa da árvore (SHINZATO; DUARTE, 2012) são fatores determinantes para os resultados alcançados.

\section{Conclusões}

A importância do índice desenvolvido, incluindo a metodologia proposta, reside na possibilidade de fornecer aos urbanistas dados quantitativos de cobertura vegetal a partir de informações disponíveis (para além da projeção 2D e altura média dos edifícios), o que pode auxiliar nas definições das políticas de uso do solo. Ressaltase que a intenção não é a de propor um índice preditivo, mas contribuir para o planejamento urbano climaticamente responsável. As limitações do índice estão relacionadas com o pequeno número de situações urbanas analisadas, de forma que os resultados não devem ser ainda generalizados, e as relações devem ser elaboradas para outras áreas e também para outras condições climáticas em estudos futuros.

Em relação às limitações da pesquisa de campo, ressalta-se o curto número de horas (recorte diurno) e dias de monitoramento. No entanto, a falta de segurança dos equipamentos em local público e a logística envolvida inviabilizaram um período maior de coleta de dados de campo. Ressalta-se, também, que os resultados encontrados estão relacionados ao tipo de árvore escolhido dentro do banco de dados do modelo ENVI-met. Recomenda-se que os cenários simulados sejam sempre o mais próximo da realidade, incluindo a modelagem da vegetação, questão a ser trabalhada em uma próxima etapa da pesquisa. Também em continuidade ao estudo, o índice deve ser contextualizado considerando situações diferentes, como arborização viária e vegetação intralote (incluindo coberturas verdes).

\section{Referências}

\section{ALI-TOUDERT, F. Dependence of Outdoor Thermal Comfort on Street Design in Hot and} Dry Climate. Freiburg, 2005. 206 f. Thesis (Meteorologischen Institutes der Universität Freiburg) - Universität Freiburg, Freiburg, 2005.

BETTINE, S. et al. Áreas Ecologicamente Estáveis Como Instrumento de Planejamento Ambiental. Interciencia, v. 37, n. 10, p. 769-774, 2012.

BOWLER, D. E. et al. Urban Greening to Cool Towns and Cities: a systematic review of the empirical evidence. Landscape Urban Plann, v. 97, p. 147-155, 2010.

BRUSE, M. ENVI-met Website. Disponível em: <http://www.envi-met.com>. Acesso em: 21 jan. 2012. 
BRUSE, M.; FLEER, H. Simulating SurfacePlant-Air Interacitions Inside Urban Environments with a Three Dimensional Numerical Model. Environmental Software and Modelling, v. 13, p. 373-384, 1998.

CAMPBELL SCIENTIFIC. Application Note: weather station siting and installation tools. 1997.

CHEN, Y.; WONG, N. H. Thermal Benefits of City Parks. Energy and Buildings, v. 38, 105120, 2006.

COHEN, P.; POTCHTER, O.; MATZARAKIS, A. Daily and Seasonal Climatic Conditions of Green Urban Open Spaces in the Mediterranean Climate and Their Impact on Human Comfort. Build Environ, v. 51, p. 285-295, 2012.

CURITBIBA. Agência de Notícias da Prefeitura de Curitiba. Índice de Área Verde Passa Para 64,5 $\mathrm{m}^{2}$ Por Habitante. 2012. Disponível em: <http://www.curitiba.pr.gov.br/noticias/indice-dearea-verde-passa-para-645-m2-por-

habitante/25525>. Acesso em: 1 abr. 2016.

CURITIBA. Agência de Notícias da Prefeitura de Curitiba. Descrição Técnica. Disponível em: <http://www.curitiba.pr.gov.br/noticias/descricaotecnica/31757>. Acesso em: 10 jan. 2014.

DUARTE, D. O Impacto da Vegetação no Microclima em Cidades Adensadas e Seu Papel na Adaptação aos Fenômenos de Aquecimento Urbano: contribuições a uma abordagem interdisciplinar. São Paulo, 2015. 167 f, Tese (Livre Docência) - Departamento de Tecnologia da Arquitetura, Universidade de São Paulo, São Paulo, 2015.

ERELL, E.; PEARLMUTTER, D.; WILLIAMSON, T. Urban Microclimate: designing the spaces between buildings. Earthscan; London: James \&James Science Publishers, 2011.

FAHMY, M.; SHARPLES, S. On the Development of an Urban Passive Thermal Comfort System in Cairo, Egypt. Building Environment, v. 44, n. 9, p. 1907-1916, 2009.

GOOGLE Inc. Google Earth. [Imagem]. Disponível em: <http://earth.google.com/>. Acesso em: 19 dez. 2012.

GOULART, S.; LAMBERTS, R.; FIRMINO, S. Dados Climáticos Para Projeto e Avaliação Energética de Edificações Para 14 Cidades Brasileiras. Florianópolis: PROCEL/Núcleo de Pesquisa em Construção da UFSC, 1998.

INSTITUTO BRASILEIRO DE GEOGRAFIA E ESTATÍSTICA. Anuário Estatístico do Brasil 2013. Rio de Janeiro: IBGE, 2014. v. 70.
INSTITUTO DE PESQUISA E

PLANEJAMENTO URBANO DE CURITIBA; FUNDAÇÃO INSTITUTO DE PESQUISAS ECONÔMICAS. Estudo de Impacto Ambiental da Operação Urbana Consorciada Linha Verde - EIA - OUCLV. São Paulo, 2012. v. I.

Disponível em:

<http://www.curitiba.pr.gov.br/conteudo/operacaourbana-eia/560>. Acesso em: 4 jan. 2013.

INTERNATIONAL ORGANIZATION FOR STANDARDIZATION. ISO 7726: ergonomics of the thermal environment: instruments of measuring physycal quantities. Switzerland, 1998.

\section{INTERNATIONAL SOCIETY OF}

BIOMETEOROLOGY. Commission 6 for the Development of a Universal Thermal Climate Index (UTCI). Freiburg: ISB Commission, 2001. Meeting Report, Freiburg, Germany, june 7-8, 2001.

JENDRITZKY, G. et al. Towards a Universal Thermal Climate Index UTCI for Assessing the Thermal Environment of the Human Being. 2009. Final Report COST Action 730.

LABAKI, L. et al. Vegetação e Conforto Térmico em Espaços Urbanos Abertos. Fórum, v. 4 , n. 1, 2011.

LEAL, L.; BIONDI, D.; BATISTA, A. C. Efeitos da Vegetação na Variação Térmica da Cidade de Curitiba, PR. Floresta, v. 44, n. 3, p. 451-464, 2014.

LOIS, E.; LABAKI, L. C. Conforto Térmico em Espaços Externos: uma revisão. In: ENCONTRO NACIONAL, 6.; ENCONTRO LATINOAMERICANO SOBRE CONFORTO NO AMBIENTE CONSTRUÍDO, 3., São Pedro, 2001. Anais... São Pedro, 2001.

MASCARÓ, L. Ambiência Urbana. Porto Alegre: Sagra, 1996.

MARTINI, A. Estudos Fenológicos em Árvores de Ruas. In: BIONDI, D.; LIMA NETO, E. M. Pesquisa em Arborização de Ruas. Curitiba: [s.l.], 2011.

MATZARAKIS, A.; RUTZ, F.; MAYER, H. Modelling Radiation Fluxes in Simple and Complex Environments: application of the RayMan model. International Journal Biometeorology, v. 51, p. 323-334, 2007.

MENDONÇA, F. Aspectos da Problemática Ambiental Urbana na Cidade de Curiitba/PR e o Mito da "Capital Ecológica". Espaço e Tempo, São Paulo, v. 12, p. 1-8, 2002. 
MINELLA, F. C. O.; HONJO, S.; KRÜGER, E. L. Estratégias de Melhoria do Ambiente Térmico Diurno em Situação de Verão de Uma Fração Urbana da Cidade de São Paulo. Ambiente Construído, Porto Alegre, v. 12, n. 4, p. 139-158, out./dez. 2012.

NG, E. et al. A Study on the Cooling Effects of Greening in High-Density City: an experience from Hong Kong. Building Environment, v. 47, p. 256-271, 2012.

OKE, T. R. Initial Guidance to Obtain Representative Meteorological Observations at Urban Sites. Geneva: World Meteorological Organization, 2006. Report N. 81, WMO/TD-No. 1250. Disponível em:

<http://www.wmo.int/pages/prog/www/IMOP/pub lications/IOM-81/IOM-81-UrbanMetObs.pdf>. Acesso em: 5 ago. 2009.

ONG, B. Green Plot Ratio: an ecological measure for architecture and urban planning. Landscape Urban Pla, v. 63, p. 197-211, 2003.

RASIA, F. B. C. Simulação e Análise da Dispersão de Poluentes nas Vias Estruturais em Curitiba, Paraná. Curitiba, 2011. $211 \mathrm{f}$. Dissertação (Mestrado em Tecnologia) - Programa de Pós Graduação em Tecnologia, Universidade Tecnológica Federal do Paraná, Curitiba, 2011.

ROSSI, F. A.; KRÜGER, E. L.; BRÖDE, P. Definição de Faixas de Conforto e Desconforto Térmico Para Espaços Abertos em Curitiba, PR, Com o Índice UTCI. Ambiente Construído, Porto Alegre, v. 12, n. 1, p. 41-59, 2012.

SATTLER, M. Dias Climáticos Típicos Para o Projeto Térmico de Edificações em Porto Alegre. Porto Alegre: CIENTEC, 1989.

SCHMITZ, L. K. Reestruturação Urbana e Conforto Térmico em Curiitba/PR: diagnóstico, modelagem e cenários. Curitiba, 2014. 298 f. Tese (Doutorado em Geografia) - Programa de Pósgraduação em Geografia, Universidade Ferderal do Paraná, Curitiba, 2014

SHINZATO, P.; DUARTE, D. Microclimatic Effect of Vegetation for Different Leaf Area Index - LAI. In: PASSIVE AND LOW ENERGY ARCHITECTURE, Lima. 2012. Proceedings... Lima: PUC Peru, 2012.
SPANGENBERG, J. et al. Simulation of the Influence of Vegetation on Microclimate and Thermal Comfort: in the city of São Paulo. Revista SBAU, Piracicaba, v. 3, n. 2, p. 1-19, 2008.

THORSSON, S. et al. Different Methods for Estimating the Mean Radiant Temperature in an Outdoor Urban Setting. International Journal of Climatology, v. 27, p. 1983-1993, 2007.

VARTHOLOMAIOS, A. et al. The Green Space Factor as a Tool for Regulating the Urban Microclimate in Vegetation-Deprived Greek Cities. In: INTERNATIONAL CONFERENCE ON "CHANGING CITIES": SPATIAL, MORPHOLOGICAL, FORMAL \& SOCIOECONOMIC DIMENSIONS, Skiathos Island, 2013. Proceedings... Skiathos Island, 2013.

WATSON, D. J. Comparative Physiological Studies on Growth of Field Crops: I. Variation in net assimilation rate and leaf area between species and varieties, and within and between years. Annals of Botany, v. 11, p. 41-76, 1947.

WIERINGA, J. et al. New Revision of Davenport Roughness Classification. In: EUROPEAN \& AFRICAN CONFERENCE ON WIND ENGINEERING, 3., Eindhoven, 2001. Proceedings... Eindhoven, 2001.

WONG, N. H.; STEVE, K. J. GIS-Based Greenery Evaluation on Campus Master Plan. Landscape Urban Plan, v. 84, n. 2, p. 166-182, fev. 2008.

WORLD METEOROLOGICAL ORGANIZATION. Guide to Meteorological Instruments and Methods of Observation: $n^{\circ} 8$. Geneva: World Meteorological Organization, 2008. Disponível em:

<http://www.wmo.int/pages/prog/gcos/documents/ gruanmanuals/CIMO/CIMO_Guide-7th_Edition2008.pdf>. Acesso em: 29 mar. 2013.

\section{Agradecimentos}

Os autores agradecem à Capes pela concessão da bolsa de doutorado. 


\section{Flavia Cristina Osaku Minella}

Programa de Pós-Graduação em Engenharia Civil, Departamento de Construção Civil | Universidade Tecnológica Federal do Paraná | Rua Deputado Heitor Alencar Furtado, 4900 | Curitiba - PR - Brasil | CEP 81280-340 | Tel.: (41) 32794521 |

E-mail: flavia.osaku@gmail.com

\section{Eduardo Leite Krüger}

Programa de Pós-Graduação em Engenharia Civil, Departamento de Construção Civil | Universidade Tecnológica Federal do Paraná |

E-mail: ekruger@utfpr.edu.br

Revista Ambiente Construído

Associação Nacional de Tecnologia do Ambiente Construído

Av. Osvaldo Aranha, $99-3^{\circ}$ andar, Centro

Porto Alegre - RS - Brasil

CEP $90035-190$

Telefone: +55 (51) 3308-4084

Fax: +55 (51) 3308-4054

www.seer.ufrgs.br/ambienteconstruido

E-mail: ambienteconstruido@ufrgs.br 